NBER WORKING PAPER SERIES

\title{
CORPORATE YIELD SPREADS: DEFAULT RISK OR LIQUIDITY? NEW EVIDENCE FROM THE CREDIT-DEFAULT SWAP MARKET
}

\author{
Francis Longstaff \\ Sanjay Mithal \\ Eric Neis \\ Working Paper 10418 \\ http://www.nber.org/papers/w10418
}

\author{
NATIONAL BUREAU OF ECONOMIC RESEARCH \\ 1050 Massachusetts Avenue \\ Cambridge, MA 02138 \\ April 2004
}

\begin{abstract}
We are grateful for valuable comments and assistance from Dennis Adler, Warren Bailey, Sanjiv Das, Darrell Duffie, Joseph Langsam, Jun Liu, Jun Pan, Eduardo Schwartz, Jure Skarabot, Soetojo Tanudjaja, and Ryoichi Yamabe, and from seminar participants at the University of California at Riverside, the London School of Business, the University of Southern California, and the University of Texas at Austin. We are particularly grateful for the comments of the Editor Robert Stambaugh and an anonymous referee. All errors are our responsibility. The views expressed herein are those of the author(s) and not necessarily those of the National Bureau of Economic Research.
\end{abstract}

CO2004 by Francis Longstaff, Sanjay Mithal, and Eric Neis. All rights reserved. Short sections of text, not to exceed two paragraphs, may be quoted without explicit permission provided that full credit, including (C) notice, is given to the source. 
Corporate Yield Spreads: Default Risk or Liquidity? New Evidence from the Credit-Default Swap Market

Francis Longstaff, Sanjay Mithal, and Eric Neis

NBER Working Paper No. 10418

April 2004

JEL No. G1

\section{ABSTRACT}

We use the information in credit-default swaps to obtain direct measures of the size of the default and nondefault components in corporate spreads. We find that the majority of the corporate spread is due to default risk. This result holds for all rating categories and is robust to the definition of the riskless curve. We also find that the nondefault component is time varying and strongly related to measures of bond-specific illiquidity as well as to macroeconomic measures of bond-market liquidity.

Francis A. Longstaff

UCLA

Anderson Graduate School of Management

110 Westwood Plaza, Box 951481

Los Angeles, CA 90095-1481

and NBER

francis.longstaff@anderson.ucla.edu

Sanjay Mithal

Deutsche Bank

Eric Neis

Anderson Graduate School of Management

UCLA 


\section{INTRODUCTION}

How do financial markets value corporate debt? What portion of corporate yield spreads is directly attributable to default risk? How much of the spread stems from other factors such as liquidity and taxes? These issues are of fundamental importance from an investment perspective since corporate debt outstanding in the U.S. now approaches $\$ 5$ trillion, making it one of the largest asset classes in the financial markets. These issues are also of key importance from a corporate finance perspective because the presence of nondefault components in corporate spreads could directly affect capital structure decisions as well as the timing of debt and equity issues.

A number of papers have studied the determinants of corporate yield spreads. Important examples include Jones, Mason, and Rosenfeld (1984), Longstaff and Schwartz (1995a), Duffie and Singleton (1997), Duffee (1999), Elton, Gruber, Agrawal, and Mann (2001), Collin-Dufresne, Goldstein, and Martin (2001), Delianedis and Geske (2001), Liu, Longstaff, and Mandell (2002), Eom, Helwege, and Huang (2003), Huang and Huang (2003), Collin-Dufresne, Goldstein, and Helwege (2003), and many others. Previously, however, researchers have been limited by having only bond data available to them in their efforts to identify the components of corporate spreads.

In the past several years, however, credit derivatives have begun trading actively in financial markets. By their nature, these innovative contracts provide researchers with a near-ideal way of directly measuring the size of the default component in corporate spreads. Credit derivatives are rapidly becoming one of the most successful financial innovations of the past decade. The British Bankers' Association estimates that from a total notional amount of $\$ 180$ billion in 1997 , the credit-derivatives market grew more than tenfold to $\$ 2.0$ trillion by the end of 2002. Furthermore, the British Bankers' Association forecasts that the total notional amount of credit derivatives will reach $\$ 4.8$ trillion by the end of 2004 .

This paper uses the information in credit-default swap premia to provide direct measures of the size of the default and nondefault components in corporate yield spreads. Credit-default swaps are the most common type of credit derivative. In a credit-default swap, the party buying protection pays the seller a fixed premium each period until either default occurs or the swap contract matures. In return, if the underlying firm defaults on its debt, the protection seller is obligated to buy back from the buyer the defaulted bond at its par value. Thus, a credit-default swap is similar to an insurance contract compensating the buyer for losses arising from a default. A key aspect of our study is the use of an extensive data set on credit-default swap premia and corporate bond prices provided to us by the Global Credit Derivatives desk at Citigroup. This proprietary data set includes weekly market quotations for a broad 
cross section of firms actively traded in the credit-derivatives market.

In measuring the size of the default component, we use two approaches. First, we use the credit-default swap premium directly as a measure of the default component in corporate spreads. As shown by Duffie and Liu (2001), however, this widely-used model-independent approach can be biased. Accordingly, we also use a reduced-form-model approach to measure the size of the default component. Specifically, we develop closed-form expressions for corporate bond prices and credit-default swap premia within the familiar Duffie and Singleton $(1997,1999)$ framework. In this reduced-form model, corporate cash flows are discounted at an adjusted rate that includes a liquidity or convenience-yield process. This feature allows the model to capture any liquidity or other nondefault-related components in corporate bond prices. For each firm in the sample, we fit the model jointly to credit-default swap premia and a cross section of corporate bond prices with maturities straddling the five-year horizon of the credit-default swaps in the sample. Once estimated, the default component is given directly from the closed-form expression for corporate bond prices. We illustrate these approaches with a detailed case study of Enron. The analysis is then extended to include all firms in the sample. To insure that the results are robust to alternative specifications of the riskless rate, we report results using the Treasury, Refcorp, and swap curves to calculate corporate spreads.

We find that the default component accounts for the majority of the corporate spread across all credit ratings. In particular, calculating spreads relative to the Treasury curve, the default component represents 51 percent of the spread for AAA/AArated bonds, 56 percent for A-rated bonds, 71 percent for BBB-rated bonds, and 83 percent for BB-rated bonds. The percentages are even higher when the other curves are used to calculate spreads.

These results contrast with those in Jones, Mason, and Rosenfeld (1984), Elton, Gruber, Agrawal, and Mann (2001), Delianedis and Geske (2001), Huang and Huang (2003), and others who report that default risk accounts for only a small percentage of the spread for investment-grade bonds. However, Elton, Gruber, Agrawal, and Mann find that spreads include an important risk premium in addition to compensation for the expected default loss. Since the credit-default swap premium measures the riskneutral default component (expected default loss plus credit-risk premium), our results may in fact be consistent with theirs. Furthermore, Delianedis and Geske and Huang and Huang show that under some parameterizations, results paralleling ours can be obtained from a structural model. Doing so, however, requires either larger jump sizes or credit-risk premia than in typical calibrations. ${ }^{1}$ Finally, Eom, Helwege, and Huang (2003) show that some structural models can actually overestimate corporate

${ }^{1}$ However, recent work by Liu, Longstaff, and Mandell (2002), Pan (2002), and CollinDufresne, Goldstein, and Helwege (2003) suggests that the market price of jumprelated risks such as default is surprisingly large in some markets. 
spreads. Thus, our results may prove useful in identifying which structural models and calibrations best explain the pricing of corporate debt.

On the other hand, our results indicate that the default component does not account for the entire corporate credit spread. Using the Treasury curve to calculate spreads, we find evidence of a significant nondefault component for every firm in the sample. This nondefault component ranges from about 20 to 100 basis points. Similarly, using the Refcorp and swap curves, we find evidence of a significant nondefault component for 96 and 75 percent of the firms in the sample, respectively.

To test whether the nondefault component is related to taxes or the illiquidity of corporate bonds, we regress the average value of the nondefault component on the coupon rate and various measures of individual corporate bond illiquidity. We find only weak evidence that the nondefault component is related to the differential state tax treatment given to Treasury and corporate bonds. In contrast, the nondefault component is strongly related to measures of individual corporate bond illiquidity such as the size of the bid/ask spread and the principal amount outstanding. We also explore the time-series properties of the average nondefault component by regressing weekly changes in its value on lagged changes and measures of Treasury richness or specialness and overall bond-market liquidity. The average nondefault component is strongly mean reverting and directly related to measures of Treasury bond richness and marketwide measures of liquidity such as flows into money market mutual funds and the amount of new corporate debt issued. These results indicate that there are important individual corporate-bond and marketwide liquidity dimensions to corporate spreads.

The literature on credit derivatives is growing rapidly. Important theoretical work in the area includes Jarrow and Turnbull (1995, 2000), Longstaff and Schwartz (1995a, b), Das (1995), Das and Tufano (1996), Duffie (1998, 1999), Lando (1998), Duffie and Singleton (1999), Hull and White (2000, 2001), Das and Sundaram (2000), Jarrow and Yildirim (2002), Acharya, Das, and Sundaram (2002), Das, Sundaram, and Sundaresan (2003), and many others. There are also several recent empirical studies of the pricing of credit-default swaps including Cossin, Hricko, Aunon-Nerin, and Huang (2002), Zhang (2003), Blanco, Brennan, and Marsh (2003), Houweling and Vorst (2004), Norden and Weber (2004), and Hull, Predescu, and White (2004). This paper differs from these other papers in that we use the information in credit-default swap premia to study the components of corporate yield spreads.

The remainder of this paper is organized as follows. Section 2 provides a brief introduction to credit-default swaps and the credit-derivatives market. Section 3 describes how the default component of corporate spreads is identified from credit-default swap and corporate bond data. Section 4 presents a case study of Enron. Section 5 presents the empirical estimates of the size of the default component in corporate spreads. Section 6 examines the properties of the nondefault component of the spread. Section 7 summarizes the results and makes concluding remarks. 


\section{CREDIT-DEFAULT SWAPS}

Credit derivatives are contingent claims with payoffs that are linked to the creditworthiness of a given firm or sovereign entity. The purpose of these instruments is to allow market participants to trade the risk associated with certain debt-related events. Credit derivatives widely used in practice include total-return swaps, spread options, and credit-default swaps. ${ }^{2}$ In this paper, we focus exclusively on the latter since they are the predominant type of credit derivative trading in the market. ${ }^{3}$

The simplest example of a single-name credit-default swap contract can be illustrated as follows. The first party to the contract, the protection buyer, wishes to insure against the possibility of default on a bond issued by a particular company. The company that has issued the bond is called the reference entity. The bond itself is designated the reference obligation. The second party to the contract, the protection seller, is willing to bear the risk associated with default by the reference entity. In the event of a default by the reference entity, the protection seller agrees to buy the reference issue at its face value from the protection buyer. In return, the protection seller receives a periodic fee from the protection buyer. This fee, typically quoted in basis points per $\$ 100$ notional amount of the reference obligation, is called the default swap premium. Once there has been a default and the contract has settled (exchange of the bond and the face value) the protection buyer discontinues the periodic payment. If a default does not occur over the life of the contract, then the contract expires at its maturity date.

As a specific example, suppose that on January 23, 2002, a protection buyer wishes to buy five years of protection against the default of the Worldcom 7.75 percent bond maturing April 1, 2007. The buyer owns 10,000 of these bonds, each having a face amount of $\$ 1,000$. Thus, the notional value of the buyer's position is $\$ 10,000,000$. The buyer contracts to buy full protection for the face amount of the debt via a single-name credit-default swap with a 169 basis point premium. Thus, the buyer pays a premium of $A / 360 \times 169$, or approximately 42.25 basis points per quarter for protection, where $A$ denotes the actual number of days during a quarter. This translates into a quarterly payment of $A / 360 \times \$ 10,000,000 \times .0169=A / 360 \times \$ 169,000$. If there is a default, then the buyer delivers the 10,000 Worldcom bonds to the protection seller and receives a payment of $\$ 10,000,000$. If the credit event occurs between default swap premium payments, then at final settlement, the protection buyer must also pay to the protection seller that part of the quarterly default swap premium that has accrued

\footnotetext{
${ }^{2}$ Credit-default swaps on a portfolio of bonds, sometimes called portfolio credit-default swaps, also exist. For example, see Fitch IBCA, Duff and Phelps (2001).

${ }^{3}$ The British Bankers' Association (2002) reports that single-name credit-default swaps are the most popular type of credit derivative, representing nearly 50 percent of the credit-derivatives market.
} 
since the most recent default swap premium payment. ${ }^{4}$ Credit events that typically trigger a credit-default swap include bankruptcy, failure to pay, default, acceleration, a repudiation or moratorium, or a restructuring.

In the most general credit-default swap contract, the parties may agree that any of a set of bonds or loans may be delivered in the case of a physical settlement (as opposed to cash settlement, to be discussed below). In this case, the reference issue serves as a benchmark against which other possible deliverable bonds or loans might be considered eligible. In any case, the deliverable obligations are usually specified in the contract. It is also possible, however, that a reference obligation may not be specified. In this case, any senior unsecured obligation of the reference entity may be delivered. Cash settlement, rather than physical settlement, may be specified in the contract. The cash settlement amount would either be the difference between the notional and market value of the reference issue (which could be ascertained by polling bond dealers), or a predetermined fraction of the notional amount. Note that because the protection buyer generally has a choice of the bond or loan to deliver in the event of default, a credit-default swap could include a delivery option similar to that in Treasury note and bond futures contracts. ${ }^{5}$

Since credit-default swaps are OTC contracts, the maturity is negotiable, and maturities from a few months to ten years or more are possible, although five years is the most common horizon. In this paper, we focus on credit-default swaps for corporates and financials with a five-year horizon. The notional amount of creditdefault swaps ranges from a few million to more than a billion dollars, with the average being in the range of $\$ 25$ to $\$ 50$ million (J.P. Morgan (2000)). A wide range of institutions participates in the credit-derivatives market. Banks, security houses, and hedge funds dominate the protection-buyers market, with banks representing about 50 percent of the demand. On the protection-sellers side, banks and insurance companies dominate (British Bankers' Association (2002)).

\section{MEASURING THE DEFAULT COMPONENT}

In this section, we describe the two approaches used to measure the size of the default component in corporate yield spreads. To be clear about definitions, corporate bond yield spreads will always be calculated as the yield on a corporate bond minus the yield on a riskless bond with the identical coupon rate and maturity date. Thus, we compare the yields on risky and riskless bonds with identical promised cash flows. ${ }^{6}$

\footnotetext{
${ }^{4}$ Worldcom filed for bankruptcy on July 21, 2002.

${ }^{5}$ For an in-depth discussion of this feature, see Mithal (2002).

${ }^{6}$ This feature is important since this allows us to measure the pure effect of default risk on yields. If the coupon and maturity are not held constant the yield spread measure
} 
In the first approach, we follow the widely-used industry practice of assuming that the credit-default swap premium equals the default component for the firm's bonds. Comparing the credit-default swap premium for a five-year contract directly with the corporate spread for a five-year bond provides a simple model-independent measure of the percentage size of the default component.

Although straightforward to implement, it is important to stress that this approach generally produces a biased measure of the default component. As shown by Duffie (1999), the credit-default swap premium should equal the spread between corporate and riskless floating-rate notes. Duffie and Liu (2001), however, show that the spread between corporate and riskless fixed-coupon bonds is generally not equal to the spread between corporate and riskless floating-rate notes. As we will show, the difference between fixed-rate and floating-rate spreads can be as much as 5 to 10 basis points or more in our sample. In general, the effect of the bias is to underestimate the size of the default component in investment-grade bonds, and vice versa for below-investment-grade bonds. This bias can be avoided by using an explicit credit model to make the adjustment from floating-rate to fixed-rate spreads. Accordingly, in our second approach, we develop a simple closed-form model for valuing creditsensitive contracts and securities within the well-known reduced-form framework of Duffie (1998), Lando (1998), Duffie and Singleton (1997, 1999) and others. Once fitted to the data, the model can then be used to provide direct estimates of the default component of the spread implied by credit-default swap premia.

Following Duffie and Singleton (1997), let $r_{t}$ denote the riskless rate, $\lambda_{t}$ the intensity of the Poisson process governing default, and $\gamma_{t}$ a convenience-yield or liquidity process that will be used to capture the extra return investors may require, above and beyond compensation for credit risk, from holding corporate rather than riskless securities. Each of the processes $r_{t}, \lambda_{t}$ and $\gamma_{t}$ is stochastic, although we assume that they evolve independently of each other. This assumption greatly simplifies the model, but has little effect on the empirical results. As in Lando (1998), we make the assumption that a bondholder recovers a fraction $1-w$ of the par value of the bond in the event of default.

Given the independence assumption, we do not actually need to specify the riskneutral dynamics of the riskless rate to solve for credit-default swap premia and corporate bond prices. We require only that these dynamics be such that the value of a riskless zero-coupon bond $D(T)$ with maturity $T$ be given by the usual expression,

$$
D(T)=E\left[\exp \left(-\int_{0}^{T} r_{t} d t\right)\right]
$$

To specify the risk-neutral dynamics of the intensity process $\lambda_{t}$, we assume that

can confound the effects of default risk with term structure effects. 


$$
d \lambda=(\alpha-\beta \lambda) d t+\sigma \sqrt{\lambda} d Z_{\lambda},
$$

where $\alpha, \beta$, and $\sigma$ are positive constants, and $Z_{\lambda}$ is a standard Brownian motion. These dynamics allow for both mean reversion and conditional heteroskedasticity in corporate spreads and guarantee that the intensity process is always nonnegative. For the risk-neutral dynamics of the liquidity process $\gamma_{t}$, we assume that

$$
d \gamma=\eta d Z_{\gamma},
$$

where $\eta$ is a positive constant and $Z_{\gamma}$ is also a standard Brownian motion. These dynamics allow the liquidity process to take on both positive and negative values. ${ }^{7}$

Following Duffie (1998), Lando (1998), Duffie and Singleton (1999) and others, it is now straightforward to represent the values of corporate bonds and the premium and protection legs of a credit-default swap as simple expectations under the risk-neutral measure. Let $c$ denote the coupon rate for a corporate bond, which for expositional simplicity is assumed to pay coupons continuously. The price of this corporate bond $C B(c, w, T)$ can be expressed as

$$
\begin{aligned}
C B(c, w, T)= & E\left[c \int_{0}^{T} \exp \left(-\int_{0}^{t} r_{s}+\lambda_{s}+\gamma_{s} d s\right) d t\right] \\
& +E\left[\exp \left(-\int_{0}^{T} r_{t}+\lambda_{t}+\gamma_{t} d t\right)\right] \\
& +E\left[(1-w) \int_{0}^{T} \lambda_{t} \exp \left(-\int_{0}^{t} r_{s}+\lambda_{s}+\gamma_{s} d s\right) d t\right] .
\end{aligned}
$$

The first term in this expression is the present value of the coupons promised by the bond, the second term is the present value of the promised principal payment, and the third term is the present value of recovery payments in the event of a default. Observe that in each term, corporate cash flows are discounted at the adjusted discount rate $r_{t}+\lambda_{t}+\gamma_{t}$.

Turning now to the valuation of the credit-default swap, it is important to recall that swaps are contracts, not securities. This distinction is important because the contractual nature of credit-default swaps makes them far less sensitive to liquidity

\footnotetext{
${ }^{7}$ We also explored alternative specifications for $\gamma_{t}$ that allow for a mean-reverting drift. These specifications generally did not perform better than Eq. (3), and often did worse because of parameter identification problems.
} 
or convenience-yield effects. First, securities are in fixed supply. In contrast, the notional amount of credit-default swaps can be arbitrarily large. This means that the types of supply and demand pressures that may affect corporate bonds are much less likely to influence credit-default swaps. Second, the generic or fungible nature of contractual cash flows means that credit-default swaps cannot become "special" in the way that securities such as Treasury bonds or popular stocks may. ${ }^{8}$ Third, since new credit-default swaps can always be created, these contracts are much less susceptible to being "squeezed" than the underlying corporate bonds. Fourth, since credit-default swaps resemble insurance contracts, many investors who buy credit protection may intend to do so for a fixed horizon and, hence, may not generally plan to unwind their position earlier. Fifth, even if an investor wants to liquidate a credit-default swap position, it may be less costly to simply enter into a new swap in the opposite direction than to try to sell his current position. Thus, the liquidity of his current position is less relevant given his ability to replicate swap cash flows through other contracts. Sixth, it can sometimes be difficult and costly to short corporate bonds. In contrast, it is generally as easy to sell protection as it is to buy protection in credit-default swap markets. Finally, Blanco, Brennan, and Marsh (2003) find that credit-derivative markets are more liquid than corporate bond markets in the sense that new information is impounded into credit-default swap premia more rapidly than into corporate bond prices.

Because of these considerations, we assume that the convenience-yield or illiquidity process $\gamma_{t}$ is applicable to the cash flows from corporate bonds, but not to cash flows from credit-default swap contracts. Alternatively, $\gamma_{t}$ can also be viewed as the differential convenience yield between corporate securities and credit-derivative contracts. Let $s$ denote the premium paid by the buyer of default protection. Assuming that the premium is paid continuously, the present value of the premium leg of a credit-default swap $P(s, T)$ can now be expressed as

$$
P(s, T)=E\left[s \int_{0}^{T} \exp \left(-\int_{0}^{t} r_{s}+\lambda_{s} d s\right) d t\right] .
$$

Similarly, the value of the protection leg of a credit-default swap $P R(w, T)$ can be expressed as

$$
P R(w, T)=E\left[w \int_{0}^{T} \lambda_{t} \exp \left(-\int_{0}^{t} r_{s}+\lambda_{s} d s\right) d t\right] .
$$

Setting the values of the two legs of the credit-default swap equal to each other and ${ }^{8}$ For example, see Duffie (1996), Duffie, Garleanu, Pederson (2002), and Geczy, Musto, and Reed (2002). 
solving for the premium gives

$$
s=\frac{E\left[w \int_{0}^{T} \lambda_{t} \exp \left(-\int_{0}^{t} r_{s}+\lambda_{s} d s\right) d t\right]}{E\left[\int_{0}^{T} \exp \left(-\int_{0}^{t} r_{s}+\lambda_{s} d s\right) d t\right]}
$$

If $\lambda_{t}$ is not stochastic, the premium is simply $\lambda w$. Even when $\lambda_{t}$ is stochastic, however, the premium can be interpreted as a present-value-weighted-average of $\lambda_{t} w$. In general, because of the negative correlation between $\lambda_{t}$ and $\exp \left(-\int_{0}^{t} \lambda_{s} d s\right)$, the premium should be less than the expected average value of $\lambda_{t}$ times $w$.

Given the square-root dynamics for the intensity process $\lambda_{t}$ and the Gaussian dynamics for the liquidity process $\gamma_{t}$, standard results such as those in Duffie, Pan, and Singleton (2000) make it straightforward to derive closed-form solutions for the expectations in Eqs. (4) and (7). Appendix A shows that the value of a corporate bond is given by

$$
\begin{gathered}
C B(c, w, T)=c \int_{0}^{T} A(t) \exp (B(t) \lambda) C(t) D(t) e^{-\gamma t} d t+ \\
A(T) \exp (B(T) \lambda) C(T) D(T) e^{-\gamma T}+ \\
(1-w) \int_{0}^{T} \exp (B(t) \lambda) C(t) D(t)(G(t)+H(t) \lambda) e^{-\gamma t} d t
\end{gathered}
$$

where $\lambda$ and $\gamma$ denote the current (or time-zero) values of the intensity and liquidity processes, respectively, and where 


$$
\begin{aligned}
A(t) & =\exp \left(\frac{\alpha(\beta+\phi)}{\sigma^{2}} t\right)\left(\frac{1-\kappa}{1-\kappa e^{\phi t}}\right)^{\frac{2 \alpha}{\sigma^{2}}} \\
B(t) & =\frac{\beta-\phi}{\sigma^{2}}+\frac{2 \phi}{\sigma^{2}\left(1-\kappa e^{\phi t}\right)}, \\
C(t) & =\exp \left(\frac{\eta^{2} t^{3}}{6}\right), \\
G(t) & =\frac{\alpha}{\phi}\left(e^{\phi t}-1\right) \exp \left(\frac{\alpha(\beta+\phi)}{\sigma^{2}} t\right)\left(\frac{1-\kappa}{1-\kappa e^{\phi t}}\right)^{\frac{2 \alpha}{\sigma^{2}}+1} \\
H(t) & =\exp \left(\frac{\alpha(\beta+\phi)+\phi \sigma^{2}}{\sigma^{2}} t\right)\left(\frac{1-\kappa}{1-\kappa e^{\phi t}}\right)^{\frac{2 \alpha}{\sigma^{2}}+2} \\
\phi & =\sqrt{2 \sigma^{2}+\beta^{2}}, \\
\kappa & =(\beta+\phi) /(\beta-\phi) .
\end{aligned}
$$

Similarly, Appendix A shows that the credit-default swap premium is given by

$$
s=\frac{w \int_{0}^{T} \exp (B(t) \lambda) D(t)(G(t)+H(t) \lambda) d t}{\int_{0}^{T} A(t) \exp (B(t) \lambda) D(t) d t} .
$$

With these closed-form solutions, our empirical approach will be to fit the model to match simultaneously the credit-default swap premium and the prices of a set of corporate bonds with maturities straddling the five-year maturity of the credit-default swap.

\section{THE ENRON CASE STUDY}

Before applying this approach to the entire sample, it is helpful to first illustrate how 
these approaches are implemented via a case study of Enron during the year leading up to its eventual default and Chapter 11 bankruptcy filing on December 2, 2001. Two primary types of Enron data are used in this case study: Credit-default swap premia and corporate bond yields.

The credit-default swap data used in this case study consist of bid and ask quotations for five-year credit-default swaps on Enron during the period from December 5, 2000 to October 22, 2001. Quotations are obtained on days when there is some level of participation in the market as evidenced either through trades or by active market making by a dealer. For Enron, we select 31 observations during the sample period, corresponding to roughly a weekly frequency, based on the availability of data on corporate bond yields and credit-default swap premia. As the point estimate of the credit-default swap premium, we use the midpoint of the bid and ask quotations. The data are provided to us by the Global Credit Derivatives desk at Citigroup. We note, however, that the data set includes quotations from a variety of credit-derivatives dealers. Thus, quotations should be representative of the entire credit-derivatives market.

Since the credit-default swaps in the sample have a five-year horizon, it would be ideal if there was always a matching five-year bond available at each observation date from which the corporate spread or probability of default could be determined. In reality, there are no Enron bonds that exactly match the five-year maturity of the credit-default swaps for any of the observation dates in the sample. Even if there were, the possibility of noise or measurement error in the bond price data would introduce volatility into the estimate of the default probability. To address these two problems, we adopt the following straightforward, and hopefully, more robust approach. Rather than focusing on a specific Enron bond, we use data from a set of bonds with maturities that bracket the five-year horizon of the credit-default swap. The process used to identify these bonds is described in Appendix B. This process resulted in a set of eight Enron bonds with maturities ranging from June 2003 to October 2007. 9 These eight bonds are all fixed-rate senior unsecured dollar-denominated debt obligations of Enron and do not have any embedded options. Only bonds that are registered with the SEC are included in the set. The coupon rates for these bonds range from 6.625 to 9.875 percent. We refer to this set of bonds as the bracketing set. The bond yield data are also obtained from a proprietary corporate bond database provided by Citigroup. Given the well-documented measurement problems associated with corporate bond data, we conducted a number of robustness checks using data for the bonds collected from the Bloomberg system to verify that our data are reliable.

${ }^{9}$ The maturity dates of the credit-default swaps associated with the first and last dates in the sample are December 5, 2005 and October 22, 2006. Thus, this set of bonds has maturities that bracket the maturity dates of the credit-default swap quotes in the sample. 
Before turning to the estimation of the default component, we first need to identify a riskless discount function $D(T)$ for each observation date. To insure that the results are robust to alternative definitions of the riskless rate, we use three different curves to generate the riskless discount function: The Treasury, Refcorp, and swap curves. We use the Treasury curve since it is the standard benchmark riskless curve in most empirical tests in finance. The use of the Refcorp curve is motivated by a recent paper by Longstaff (2004) that shows that Refcorp bonds have the same default risk as Treasury bonds but not the same liquidity or specialness of Treasury bonds. Thus, the Refcorp curve may provide a more accurate measure of the riskless curve than the Treasury curve. Finally, we use the swap curve since this curve is widely used by practitioners to discount cash flows in fixed income derivatives markets. As shown by Duffie and Singleton (1997) and Liu, Longstaff, and Mandell (2002), however, the swap curve includes both credit and default components.

For the Treasury curve, we collect data for the constant maturity six-month, oneyear, two-year, three-year, five-year, seven-year, and ten-year rates from the Federal Reserve. We then use a standard cubic spline algorithm to interpolate these par rates at semiannual intervals. These par rates are then bootstrapped to provide a discount curve at semiannual intervals. To obtain the value of the discount function at other maturities, we use a straightforward linear interpolation of the corresponding forward rates. For the Refcorp curve, we collect three-month, six-month, one-year, two-year, three-year, five-year, seven-year, and ten-year zero-coupon yields directly from the Bloomberg system which uses a bootstrap algorithm very similar to that described above. We then use the same approach of linearly interpolating forward rates to obtain the discount function for other maturities. Finally, we collect constant maturity three-month, six-month, one-year, two-year, three-year, five-year, seven-year, and ten year swap rates from the Bloomberg system and follow the same algorithm as that described above for the Treasury curve to obtain swap discount functions. In each case, we collect data for a ten-year horizon since all of the corporate bonds in our sample have a maturity of ten years or less.

To compute the corporate spread, we use the following procedure. For each corporate bond in the bracketing set, we solve for the yield on a riskless bond with the same maturity date and coupon rate. Subtracting this riskless yield from the yield on the corporate bond gives the yield spread for that particular corporate bond. To obtain a five-year-horizon yield spread for the firm, we regress the yield spreads for the individual bonds in the bracketing set on their maturities. We then use the fitted value of the regression at a five-year horizon as the estimate of the corporate spread for the firm. Fig. 1 plots the yield spread, the credit-default swap premium, and the stock price for Enron during the sample period. Recall that in the modelindependent approach, the credit-default swap premium is used as the estimate of the default component of the corporate spread. As shown, the credit-default swap premium frequently diverges from the corporate yield spread. 
To estimate the parameters for the intensity and liquidity processes, we do the following. First, we pick trial values for the parameters $\alpha, \beta, \sigma$, and $\eta$. For each of the 31 observation dates, we have the five-year credit-default swap premium and yields for a subset (ranging from three to eight, and averaging four) of the Enron bonds in the bracketing set described above. Given the parameters and for each date, we solve for the value of $\lambda_{t}$ that matches exactly the value of the credit-default swap premium and for the value of $\gamma_{t}$ that results in the best root-mean-square fit of the model to the bond yields for that date. ${ }^{10}$ We repeat this process for all 31 observation dates and compute the root-mean-squared error over all of the 31 observation dates. We then pick another trial value of the parameters, and repeat the entire process. Convergence occurs by searching over parameter values until the global minimum value of the overall rootmean-squared error is obtained. ${ }^{11}$ Throughout this procedure, we hold the recovery percentage $w$ constant at 50 percent. ${ }^{12}$ However, the estimation results are virtually identical when other values of $w$ are used.

This estimation approach has several key advantages. Foremost among these is that by fitting to a cross section of bonds with maturities that bracket that of the credit-default swap, we minimize the effect of any measurement error in individual bond prices on the results. In essence, by using a cross section of bonds, we attempt to "average out" the effects of idiosyncratic pricing errors in individual bonds. Nonetheless, $\lambda_{t}$ by design captures the default risk of the firm because its value is chosen to fit the credit-default swap premium exactly, while $\gamma_{t}$ is chosen to fit the bond prices as well as possible. Thus, $\gamma_{t}$ captures the nondefault yield spread associated with bonds in the bracketing set.

This process results in estimates of the four parameters $\alpha, \beta, \sigma$, and $\eta$ of the riskneutral dynamics as well as for the values of $\lambda_{t}$ and $\gamma_{t}$ for each of the 31 observation dates in the sample. The overall root-mean-squared error from the fitting procedure ranges from about 10 to 17 basis points, depending on which discounting curve is used. These fitting errors are relatively small given the large variation in Enron spreads during the sample period. ${ }^{13}$

${ }^{10}$ In doing this, we fit the market bond and credit-default swap data to discrete versions of Eqs. (8) and (9) that match the actual semiannual timing of coupon payments and the quarterly timing of swap premia (rather than assuming that cash flows are paid continuously).

${ }^{11}$ As a further identification condition, we require that the estimated values of $\sigma$ and $\eta$ be consistent with the volatilities of changes in the estimated $\lambda_{t}$ and $\gamma_{t}$ values.

${ }^{12} \mathrm{~A} 50$ percent recovery rate is consistent with the median value for senior unsecured bonds reported in Duffie and Singleton (1999).

${ }^{13} \mathrm{We}$ also estimate the parameters using a specification in which we fit to the prices of the bonds, rather than the yields of the bonds. The results are nearly identical to those reported. 
The top panel of Fig. 2 plots the implied values of the intensity process $\lambda_{t}$ for each of the 31 observation dates. As shown, the implied default intensities are almost the same for each of the three discounting curves. The implied default intensity rises slowly from a level of about 150 basis points at the end of 2000 to about 250 basis points near the end of August 2001. Around the second week of October 2001, however, the implied default intensity increases rapidly to more than 800 basis points. Table 1 provides a chronology of some of the events leading up to Enron's bankruptcy. The chronology shows that the first indications of major financial problems at Enron surfaced in the press around October 16, 2001. Enron's debt was downgraded by Standard and Poor's to B- on November 28, 2001, and to CC on November 30, 2001. Enron filed for bankruptcy and defaulted on its debt on December 2, 2001. Note that the last observation in our sample is dated October 22, 2001.

The middle panel of Fig. 2 plots the implied values of the liquidity process $\gamma_{t}$. The average value of the liquidity process is 8.1 basis points when the Treasury curve is used, -27.0 basis points when the Refcorp curve is used, and -66.4 basis points when the swap curve is used. The liquidity process is fairly constant throughout most of the sample period, but declines rapidly as the implied probability of a default begins to increase in August 2001 (but not one-to-one with the increase in $\lambda$ ).

To solve for the default component for a corporate bond, we substitute the estimated parameters $\alpha, \beta$, and $\sigma$ and the value of $\lambda$ into Eq. (8). Rather than substituting in the implied values of $\eta$ and $\gamma$, however, we set their values equal to zero in Eq. (8), or equivalently, set the value of $\gamma$ equal to zero and the value of $C(T)$ equal to one. This gives the value of the corporate bond under the assumption that $\gamma$ is currently zero and remains at zero since $\eta=0$ implies $d \gamma=0$. This value for the corporate bond can be viewed as its liquidity-adjusted price, or alternatively, the price at which the bonds would trade if there was no liquidity or convenience-yield process $\left(\gamma_{t}=0\right.$ for all $\left.t\right)$. The default component is now obtained by taking the yield implied by the liquidity-adjusted corporate bond price and subtracting the yield on a riskless bond with identical promised cash flows. To solve for the default component in the five-year-horizon yield for a firm, we follow the same regression approach described earlier for yield spreads in that we regress the default components for the bonds in the bracketing set on the maturities of the bonds and use the five-year fitted value as the default component for the firm. To simplify the exposition, we will refer to the default component for an individual bond and the five-year-horizon default component for a firm simply as the default component whenever the context is clear. We adopt the same convention in discussing yield spreads for individual bonds or firms.

The bottom panel of Fig. 2 shows that there is a sizable difference between the default component for Enron and the credit-default swap premium. On average, the default component is about 6 basis points higher than the credit-default swap premium. Given that the nondefault component of the spread is only 8.1 basis points on average, the bias arising from using the credit-default swap premium as the measure 
of the default component is relatively large. There is also a significant amount of time variation in the bias. In particular, the credit-default swap premium is a downward biased estimate of the default component during the early part of the sample when spreads are tighter, but becomes an upward biased estimate as Enron approaches bankruptcy. These results confirm that it is important to use a model-based approach in estimating the components of the corporate spread.

The top panel of Fig. 3 plots the default component as a percentage of the total spread when the Treasury curve is used. On average, default accounts for 90 percent of the spread. However, there is significant time variation in this default proportion. The default proportion is around 75 percent at the beginning of the sample period, but then rises to nearly 100 percent for much of the first half of the period. The default proportion then declines to about 70 to 80 percent in the summer, and finally rises to more than 90 percent as Enron begins to approach financial distress. The middle and bottom panels of Fig. 3 plot the percentages using the Refcorp and swap curves.

\section{THE DEFAULT COMPONENT}

Having illustrated our approach with Enron, we now extend the analysis to a large sample of firms using an extensive data set provided by Citigroup. This data set includes credit-default swap premia for five-year contracts and corresponding corporate bond prices for 68 firms actively traded in the credit-derivatives market during the March 2001 to October 2002 period. ${ }^{14}$ Details of how the data set is constructed are described in Appendix B.

To estimate the size of the default component for each firm, we follow the same process as for Enron in collecting data for bonds with maturities bracketing the fiveyear horizon of the credit-default swaps as well as meeting the other criteria described in Appendix B. The set of bonds included in the sample for each firm is again referred to as the bracketing set. The number of bonds in the bracketing set varies by firm. The minimum number of bonds used is two and the maximum number of bonds is 18 . Since not all bonds have price data for every date for which we have credit-default swap data, the average number of bonds used to estimate the default component on a particular date can be less than the total number of bonds in the bracketing set.

As a preliminary analysis, Table 2 reports the ratio of the default component for the firms in the sample to the total yield spread when the model-independent approximation is used. Specifically, we report the ratio of the credit-default swap premium to the total spread for each firm. The results are reported separately for each of the three curves used as the riskless discounting curve. In each panel, we also report the average credit-default swap premium and average total corporate spread

${ }^{14}$ The data for Enron are from December 2000 to October 2001. 
along with the ratio. The asterisk next to a ratio indicates that the ratio is statistically different from 1.00 .

As shown, the ratio of the credit-default swap premium to the total corporate spread varies widely across firms. As discussed earlier, the size of the default component for investment-grade bonds tends to be higher than reported in previous studies. On the other hand, the size of the default component for the BB-rated bonds is much closer to that reported in earlier papers such as Huang and Huang (2003). To be specific, when the Treasury curve is used as the riskless curve, the percentage of the total spread explained by the model-independent estimate of the default component is 49 percent for AAA/AA-rated bonds, 53 percent for A-rated bonds, 68 percent for BBBrated bonds, and 84 percent for below-investment-grade bonds. The corresponding ratios are all higher when the Refcorp or swap curves are used as the riskless curve. ${ }^{15}$

We next repeat the process described in the previous section to estimate the riskneutral parameters and values of $\lambda_{t}$ and $\gamma_{t}$ for each of the firms in the sample. Table 3 reports the average values of the two processes for each firm, along with the fraction that the average value of $\lambda_{t}$ represents of the average value of $\lambda_{t}+\gamma_{t}$. This fraction can be viewed as a measure of the instantaneous default component, or the proportion of the spread on short-term bonds due entirely to default risk. Again, the asterisk next to a fraction denotes that the fraction is statistically different from 1.00.

Table 3 shows that the instantaneous default component tends to be a larger percentage of the total spread than is the case in Table 2. When the Treasury curve is used as the riskless curve, the proportion of the instantaneous spread explained by default is 62 percent for AAA/AA-rated bonds, 63 percent for A-rated bonds, 79 percent for BBB-rated bonds, and 89 percent for the BB-rated bonds. Again, the percentages are higher when the Refcorp and swap curves are used as the riskless curve.

Table 4 reports the model-based estimates of the size of the default component in the yield spread for the firms in the sample. As shown, the proportion of the spread explained by default risk averages more than 50 percent across all credit-rating categories and choices of the riskless curve. When the Treasury curve is used as the riskless curve, the average size of the default component ranges from 51 percent for AAA/AA-rated bonds to 83 percent for BB-rated bonds. When the Refcorp curve is used, the corresponding percentages range from 62 percent to 86 percent. Interestingly, when the swap curve is used as the riskless curve, the proportion due to default is 116 percent for AAA/AA-rated bonds, 89 percent for A-rated bonds, 94 percent for BBB-rated bonds, and 95 percent for BB-rated bonds. Intuitively, the reason why the swap curve implies default components greater that 100 percent of the corporate spread in some cases is that the swap curve probably includes a credit component

${ }^{15}$ The rating reported for each firm is the rating on the last date of the sample period for that firm. 
itself. Thus, firms with higher credit ratings than those in the basket of 16 banks used in the official Libor fixing tend to have negative values for the liquidity process $\gamma_{t}$, which, in turn, implies a negative nondefault component.

Although not shown, we also examine the percentage of the variation in corporate spreads explained by the default component. This is done by regressing the time series of the yield spread for each firm on the estimated default component for that firm. The $R^{2}$ s from these regressions, using the Treasury curve, average 0.37 for the AAA/AArated bonds, 0.43 for the A-rated firms, 0.57 for the BBB-rated firms, and 0.62 for the BB-rated firms. The results using the Refcorp and swap curves are very similar or slightly higher. Overall, the average $R^{2}$ across all firms is about 0.51 . Thus, the default component represents the majority of the corporate spread not only in size, but also generally in terms of the percentage of time-series variation explained.

Comparing the size of the default component in Table 4 with that from the modelindependent estimate reported in Table 2 again shows that the model-independent approach is biased. When the Treasury curve is used as the riskless curve, the difference between the estimated default components in Table 4 and Table 2 is 2.8 basis points for AAA/AA-rated bonds, 3.6 basis points for A-rated bonds, 6.6 basis points for BBB-rated bonds, and -1.7 basis points for BB-rated bonds. ${ }^{16}$ Failing to correctly account for this bias could potentially have unfortunate effects in drawing inferences about the size and statistical properties of the default and nondefault components of corporate spreads.

Although Table 4 shows that the majority of the corporate yield spread is due to default risk, Table 4 also shows that default risk does not explain all of the corporate spread. When the Treasury curve is used as the riskless curve, we find that the default component is reliably smaller than the total spread for each of the 68 firms in the sample. When the Refcorp and swap curves are used as the riskless curve, 96 and 75 percent of the ratios are significantly different from 1.00, respectively. Thus, our results about the existence of a significant nondefault component are robust to the choice of the riskless discounting curve.

One important issue to consider is whether our results underestimate the size of the default component because of the effects of counterparty-credit risk. If there is a risk that the party selling credit protection might enter into financial distress itself and be unable to meet its contractual obligations, then the value of the promised protection is obviously not worth as much to the buyer. In this situation, the premium that the buyer would be willing to pay would be correspondingly less. To keep things as simple as possible in exploring this issue, assume that with probability $p$ the protection seller is unable to meet his contractual obligations. Furthermore, assume that the default by

\footnotetext{
${ }^{16}$ Seven of the firms in the sample have absolute biases in excess of ten basis points, and the model-independent approach underestimates the size of the default component for all but one of the investment-grade firms.
} 
the protection seller is independent of default on the underlying reference obligation. In this simple case, the value of the protection leg is now only worth $(1-p)$ times the value given in Eq. (6). In turn, this means that the protection buyer would only be willing to pay $(1-p) s$, where $s$ is the value given in Eq. (7). Given this, it is now easy to answer the question: How large would the probability of counterparty default need to be to conclude that the corporate spread is entirely due to default risk? The answer is 1.00 minus the default component ratio shown in Table 4 . For example, using the Treasury curve, the average ratio for AAA/AA-rated bonds is 0.51. Thus, the probability of a counterparty default would need to be 0.49 , or 49 percent, for the yield spread of these bonds to be due entirely to default risk. This is orders of magnitude larger than any realistic estimate of the default risk of the large investement-grade firms selling credit protection even over a five-year horizon. Similar conclusions follow for the other ratings categories in the sample. Finally, the fact that the size of the nondefault component varies across ratings categories also argues against the nondefault component being due to counterparty credit risk. If the nondefault component was due to counterparty credit risk, there would be more uniformity in its size. This follows since the set of counterparties selling protection is likely to be very similar across all of the firms in the sample. In summary, counterparty credit risk is unlikely to account for much of the nondefault component of spreads.

Another issue to consider is whether the larger estimates of the default component we find are due to illiquidity in the credit-derivatives market. The answer to this is clearly no since the most likely effect of illiquidity, if any, in the credit-derivatives market would actually be to understate the size of the default component. To see this, consider a market in which corporate bonds trade at a discount to their fair value because of their illiquidity. In this market, the protection leg of a credit-default swap would likely be worth less than its theoretical value because, similar to the cash flows from a bond, it is a credit-sensitive cash flow. In contrast, the premium leg of the credit-default swap is a completely generic fixed annuity similar to that for any interest rate swap. Thus, since both legs of a credit-default swap have to have the same value at the inception of the swap (the zero net-present-value condition for swaps), the premium that a protection buyer would be willing to pay would need to be less since the value of the illiquidity-impaired protection leg is less. This means that if there is any illiquidity component in credit-default swap premia, then we may be underestimating the size of the default component. Thus, finding that the majority of corporate spreads is due to default risk is likely not an artifact of the effects, if any, of illiquidity on credit-default swap premia. ${ }^{17}$

\footnotetext{
${ }^{17}$ As another robustness check, we reestimated the default component using the assumption that $w=1$ rather than $w=.50$. The results are virtually the same as those reported here. Intuitively, the reason why the results are not sensitive to the assumption about recovery is that $w$ is used symmetrically in the bond price and credit-default swap premium; the effects of $w$ largely wash out in the calibration pro-
} 


\section{THE NONDEFAULT COMPONENT}

In this section, we examine the properties of the nondefault component of the spread, which is given by simply subtracting the default component of the spread from the total spread. The average nondefault component for each firm can be obtained directly from Table 4 by subtracting the default component in each panel from the corresponding corporate spread.

Fig. 4 plots histograms of the average nondefault component for each firm in the sample. As shown, there is considerable cross-sectional variation in the nondefault components. Using the Treasury curve, the nondefault components range from 18.8 to 104.5 basis points, with a mean of 65.0 . Using the Refcorp curve, the nondefault components range from -8.1 to 89.8 basis points with a mean of 47.7. Similarly, using the swap curve, the nondefault components range from -57.8 to 50.5 basis points with a mean of 8.6.

Fig. 5 plots the average default and nondefault components by rating category. As shown, both the average default and nondefault components increase as the rating category declines. However, the plots show that the rating-related variation in the default component is much stronger than for the nondefault component. For example, when the Treasury curve is used, the default component ranges from 53.3 basis points to 356.0 basis points, while the nondefault component ranges from 50.3 to 71.8 basis points. Thus, compared to the default component, the nondefault component is nearly constant across rating categories.

Many previous studies have found evidence of nondefault components in corporate spreads. Important examples include Jones, Mason, and Rosenfeld (1984), Duffie and Singleton (1997), Duffee (1999), Elton, Gruber, Agrawal, and Mann (2001), Delianedis and Geske (2001), Collin-Dufresne, Goldstein, and Martin (2001), Liu, Longstaff, and Mandell (2002), Huang and Huang (2003), and Eom, Helwege, and Huang (2003). Typically, these studies find evidence that the nondefault component is related to tax or liquidity factors. Motivated by this, we explore the determinants of the nondefault component from both a cross-sectional and time-series perspective using a number of tax and liquidity-related explanatory variables.

\subsection{Cross-Sectional Analysis.}

We focus first on the cross-sectional variation in the time-series averages of the nondefault component. Our approach in doing this is to regress the nondefault component for individual bonds on a number of explanatory variables suggested by theoretical considerations.

cedure. Another way of seeing this is to note that a portfolio consisting of a corporate bond and credit protection is very nearly the same as a riskless bond irrespective of the assumptions made about recovery. 
One important feature that could drive a wedge between the yields on corporate and Treasury bonds is that interest on Treasury bonds is exempt from state and local income taxes, while interest on corporate bonds is not. Note, however, that this asymmetry does not apply to the spread between corporate and Refcorp bonds, or corporate bonds and swaps. In a recent paper, Elton, Gruber, Agrawal, and Mann (2001) argue that the asymmetry in taxation between corporates and Treasuries might explain a significant portion of the yield spread between corporates and Treasuries. Since credit-default swaps are purely contractual in nature, the premium should reflect only the actual risk of default on the underlying bonds. Thus, if the spread between corporates and Treasuries includes a tax-related component in addition to the defaultrelated component, then this portion of the spread should not be incorporated into the credit-default swap premium. Of course, the size of any tax-related component in corporate spreads will depend on the marginal state and local tax rate of the marginal investor in the corporate bond market. The recent trend toward greater participation in the corporate bond markets by pension, retirement, $401 \mathrm{k}$, and other tax-exempt investors, however, raises the possibility that the marginal state and local tax rate could be very small or even zero. ${ }^{18}$ Note that any tax-related component in yield spreads would be linked to bond-specific features such as the coupon rate of the corporate bond. ${ }^{19}$

To test for tax effects, we use the coupon rate of the bonds as an explanatory variable. The intuition for using this variable is that an investor with a marginal tax rate of $\tau$ would need to receive a pre-tax coupon of $c /(1-\tau)$ to have an after-tax coupon of $c$. Thus, the markup in the coupon to compensate for the additional state and local taxes incurred by corporate bonds should be roughly proportional to the coupon rate of the bonds. By including the coupon rate in the regression, we allow for the possibility that the spread includes a tax-related component.

Another possible determinant of the nondefault component is the illiquidity of individual corporate bonds relative to the benchmark riskless curve. For example, if corporate bonds are less liquid than Treasury or Refcorp bonds and priced accordingly, then corporate spreads could also include a liquidity component. Thus, the liquidity

\footnotetext{
${ }^{18}$ Sarig and Warga (1989) and Delianedis and Geske (2001) report that market participants view tax-exempt pension funds as the dominant players in the corporate bond markets.

${ }^{19}$ The effects of taxation on the credit-default swap premium itself have not been studied in the literature. We conjecture, however, that any effect would be small. The reason for this is that the market is currently limited to large institutions rather than individuals, and that for most of these institutions, cash flows and mark-to-market gains and losses from swaps are taxed as ordinary income. Furthermore, the tax treatment of both legs of a credit-default swap is the same; there is no tax asymmetry driving a wedge between the values of the premium and protection legs of the swap.
} 
of the corporate bonds (or lack thereof relative to the bonds defining the riskless curve used to estimate the $D(T)$ function) should not affect the cost of credit protection in the credit-default swap market. ${ }^{20}$

To test whether cross-sectional differences in the nondefault component reflect the relative illiquidity of individual bonds, we regress the nondefault component for each bond in the sample on a number of liquidity proxies for these bonds. In doing this, it is important to acknowledge that liquidity is a concept that is sometimes difficult even to define, much less to quantify. Accordingly, our approach focuses on proxies that reflect different interpretations of liquidity and are based on available data. Unfortunately, measures of trading activity or volume are not available to us. Also, we do not have measures of the "specialness" or costs of shorting individual corporate bonds. As shown in Duffie (1996), these costs often mirror the relative liquidity of securities. ${ }^{21}$

The first proxy is the average bid-ask spread (in basis points) of the corporate bonds in the bracketing set. The bid-ask spread for each bond is calculated by taking the time-series average of the daily bid-ask spread reported by Bloomberg. These average bid-ask spreads range from about 4 basis points to more than 15 basis points. ${ }^{22}$

The second proxy attempts to measure the general availability of the bond issue in the market. In particular, we use the notional amount outstanding of each bond as a proxy for the bond's liquidity.

The third proxy is the age of the bond. This proxy parallels the notion of onthe-run and off-the-run bonds in Treasury markets. There is extensive evidence that on-the-run Treasury bonds are much more liquid than off-the-run Treasury bonds. If there is a similar effect in the corporate bond market, then older bonds may be less liquid than more-recently issued bonds.

The fourth proxy is the time to maturity of the bond. The intuition for this variable is that there may be maturity clienteles for corporate bonds. Thus, it is possible, for example, that shorter-maturity corporate bonds may be more liquid than

${ }^{20}$ Empirical studies documenting the presence of liquidity-related premia in Treasury bond prices include Amihud and Mendelson (1991), Kamara (1994), and Longstaff (2004).

${ }^{21}$ To provide some perspective, we contacted several securities dealers about the costs of shorting corporate bonds. For liquid corporate bonds, the cost of shorting is only on the order of five basis points. We note, however, that in rare cases (typically related to firms in financial distress) corporate bonds can trade special by as much as 50 to 75 basis points for brief periods of time.

${ }^{22}$ Bid-ask spreads are calculated for bonds with Bloomberg "generic" prices, signifying a consensus among market participants regarding the value of the bond. So called "fair value" prices, where a bond is priced by Bloomberg using matrix-pricing techniques, are not used in the calculation of the overall bid-ask spread. 
longer-maturity bonds. If so, then the difference in maturities across bonds may be related to cross-sectional differences in the nondefault component.

The fifth proxy is a dummy variable for bonds issued by financial firms. Since financial firms are presumably more connected to the capital markets, their securities may enjoy greater liquidity than the securities of other firms. ${ }^{23}$

The sixth and final proxy for bond-specific illiquidity is a dummy variable for bonds issued by highly-rated firms, i.e. firms with a credit rating of AAA or AA. The intuition for this proxy is that there may be a "flight-to-quality" premium in highly-rated bonds because they may be more marketable during a market panic or crisis. If so, then their liquidity may be more comparable to that of Treasury bonds. In turn, this implies that there might be a smaller nondefault component in the spread of AAA/AA-rated bonds.

Table 5 reports the results from the regression of the nondefault component for each bond in the sample on the tax and liquidity variables. As shown, the coupon rate of the bond is significant at the five-percent level for the Treasury and swap curves, and significant at the ten-percent level for the Refcorp curve. The regression coefficient for the Treasury regression is 5.441 which is easily in the range of realistic marginal state income rates. ${ }^{24}$ While it may be tempting to interpret this as evidence consistent with the tax hypothesis, the results for the other curves are not so easy to interpret. In particular, the tax difference described above applies only to corporate bonds vs. Treasuries. In contrast, the state tax treatment of Refcorp bonds and swaps is essentially the same as that of corporate bonds. Thus, it is difficult to interpret the significant coefficients for the coupon rate in the Refcorp and swap regressions as a tax effect. In fact, these significant coefficients may simply be capturing the fact that higher-coupon bonds may be less popular or less liquid than other bonds. ${ }^{25}$ If so, only the difference between the regression coefficient in the Treasury regression and the regression coefficients in the other regression may be unambiguously interpreted as a tax effect. Subtracting 3.178 or 3.637 from 5.441 implies that the actual marginal state tax rate incorporated into these bonds may only be on the order of one to two percent.

Turning to the measures of corporate-bond illiquidity, Table 5 also shows that the average bid-ask spread of the corporate bonds is significantly positively related to the nondefault component in all three regressions. Thus, as the liquidity of the corporate bonds decreases, the size of the nondefault component increases. This is consistent with the hypothesis that less-liquid bonds tend to have a larger liquidity component

${ }^{23}$ Ford Motor Credit and GMAC are treated as financial firms in this analysis.

${ }^{24}$ The top marginal state income tax rate ranges from zero for a number of states to 9.3 percent for California and 10.4 percent for New York.

${ }^{25}$ We are grateful to the referee for pointing out this possibility. 
embedded within their yield spreads, and that this component is not included in market credit-default swap premia. The principal amount of the bond outstanding is significantly negatively related to the nondefault component in each regression. These results are also consistent with a liquidity interpretation. In particular, the nondefault component is smaller for bonds with larger issue sizes, which are presumably more liquid or easy to find in the financial markets.

The coefficient for the age of the bond is not significant in any of the three regressions reported in Table 5 . This may be possible evidence against the existence of an on-the-run effect in the corporate bond market. It is important to raise the caveat, however, that the age of the bonds in the sample ranges from about 1 year to more than 10 years; newly-issued or on-the-run issues are rare in the sample. Thus, the bonds in the sample may simply all be off-the-run bonds. In this case, it may be unsurprising that we find no cross-sectional effects. In contrast, there is a strong positive relation between the nondefault component and the time to maturity of the bond. Thus, these results are consistent with the interpretation that longer-maturity bonds are less liquid than shorter-maturity bonds.

Both of the dummy variables are significant. Surprisingly, the coefficient for the financial dummy variable is positive in sign. This suggests that there is an additional 11 to 13 basis points in the nondefault component of financial firms. This is not consistent with the hypothesis that debt issued by financial firms is more liquid or more readily marketable than debt for other firms. On the other hand, these results do indicate that there are industry effects in the nondefault component of corporate spreads. The regression coefficient for the AAA/AA dummy variable is significant and negative, and is about -12 or -13 basis points. This is supportive of the presence of a small but significant "flight-to-quality" or "flight-to-liquidity" premium in the prices of the highest-rated corporate bonds.

\subsection{Time-Series Analysis.}

Turning now to the time-series properties of the nondefault component, we observe that there are two ways in which a liquidity component in corporate spreads could arise. The first is through the idiosyncratic illiquidity of individual corporate bonds. The effect of this would be to create cross-sectional variation in the nondefault component across bonds. The regression results in Table 5 are consistent with the presence of bond-specific illiquidity components in corporate spreads. The second way is if Treasury (or Refcorp or other benchmark) bonds trade at a premium because of their unique role in financial markets as highly-liquid or marketable havens during turbulent periods (for example, during flights to quality or liquidity). In this case, corporate spreads will contain a common Treasury liquidity component. The effect of this Treasury-specific richness or liquidity would be to increase the measured spread for all corporate bonds. Thus, this effect would show up only in the common time-series variation in the nondefault components, not in the cross section of the nondefault components. 
To test whether there is variation in the nondefault component arising from changes or systematic shocks to marketwide liquidity measures, we average the nondefault component over firms and regress weekly changes in this measure on changes in several macroeconomic measures of Treasury and corporate bond market liquidity. Fig. 6 plots the time series of the average nondefault component. The first measure is motivated by recent work by Longstaff (2004), who finds that liquidity spreads in the Refcorp market are related to flows into money market mutual funds. Accordingly, we obtain weekly changes in total money market mutual fund assets from the Federal Reserve Board and include the sum of the two previous weekly changes as an explanatory variable. The intuition for this variable is that money market mutual funds represent a hedge against flights to quality or liquidity. A sudden increase in the amount of funds flowing into money market mutual funds may be associated with a general lack of liquidity in more-risky markets such as the corporate bond market. This systematic liquidity shock would appear as a general widening in the spreads between all corporate bonds and Treasury or other benchmark bonds.

The second measure is the weekly dollar amount of corporate (including agency) debt issued in the fixed income markets. This measure is obtained from the Bloomberg system. If there is a large inflow of new debt in the market, the liquidity of older corporate bonds may be impaired. This would translate into a widening in the nondefault component for the bonds in our sample. Again, this variable measures marketwide liquidity rather than bond-specific illiquidity.

The third measure is the difference in the yield of the current on-the-run five-year Treasury bond and the average yield of generic off-the-run Treasury bonds. As the on-the-run yield, we use the constant maturity five-year Treasury rate calculated by the Federal Reserve from benchmark on-the-run issues. The off-the-run yield is the five-year generic Treasury rate reported in the Bloomberg system and which is based on the yields of nonbenchmark Treasury bonds. The spread between on-the-run and off-the-run bonds reflects the specialness or liquidity of Treasury bonds (see Duffie (1996)). This spread is also related to the financing advantage of on-the-run Treasury bonds in the special repo market (see Jordan and Jordan (1997), Buraschi and Menini (2002), and Krishnamurthy (2002)).

Table 6 reports the result from regressing the weekly changes in the average nondefault component on the three proxies as well as the lagged change in the nondefault component. As shown, the coefficient for the lagged change in the nondefault component is negative and highly significant. This demonstrates that the nondefault component is both time varying and mean reverting. Furthermore, the magnitude of the regression coefficients suggests that the speed of mean reversion is very rapid; that shocks to the nondefault component tend to dissipate within a few weeks or months.

The coefficient for the change in money market mutual fund assets is positive and significant at the five-percent level for the Treasury and swap regressions, and positive and significant at the ten-percent level for the Refcorp regression. Thus, as money flows 
into defensive money market positions, the nondefault component of corporate spreads increases. This is consistent with the interpretation of the nondefault component as a liquidity-related component.

The amount of debt issued has a positive sign but is not significant at conventional levels in the Treasury and Refcorp regressions. For the swap regression, however, the amount of debt is positively and significantly related to the nondefault component. This supports the view that as the market absorbs new debt, existing issues become less liquid.

The coefficient for the on-the-run/off-the-run spread is positive and significant at the five-percent and ten-percent levels respectively for the Refcorp and swap regressions. This provides direct evidence that as the richness or extreme liquidity of Treasury bonds increases, the average nondefault component of all corporate bonds increases. This again supports the hypothesis that an important portion of the nondefault component of corporate spreads is due to the liquidity of the Treasury bonds.

\subsection{Discussion.}

Taken together, the cross-sectional and time-series results indicate that the nondefault component of corporate bond spreads is strongly related to a number of liquidity measures. Bond-specific illiquidity measures are important in explaining cross-sectional differences, while marketwide or macroeconomic measures of liquidity explain a sizable portion of the common variation in all corporate spreads. This evidence of strong marketwide components in corporate spreads is clearly consistent with the evidence in Collin-Dufresne, Goldstein, and Martin (2001) about the commonalities in corporate spreads. In fact, they argue that the presence of an aggregate liquidity factor in bond markets may explain most of the movements of credit spreads. Similarly, Duffie and Singleton (1997), Delianedis and Geske (2001), Liu, Longstaff, and Mandell (2002), and Longstaff (2004) find consistent evidence that time variation in corporate spreads is related to systematic liquidity shocks. Finally, Pastor and Stambaugh (2003), Wang (2003), Acharya and Pederson (2003) and others find evidence that variation in liquidity is a risk that is priced in equity markets.

\section{CONCLUSION}

In this paper, we use the information in credit-default swaps to provide direct evidence about the size of the default and nondefault components in corporate spreads. An important feature of our analysis is the use of an extensive dataset on credit-default swap premia and the corresponding corporate bond prices provided to us by the Global Credit Derivatives desk at Citigroup.

The results indicate that the default component represents the majority of corporate spreads. Even for the highest-rated investment-grade firms in the sample, default risk accounts for more than 50 percent of the total corporate spread. These results 
complement and extend previous work by suggesting that the market price of credit risk may be larger than implied by some structural models. Alternatively, marketimplied risk-neutral estimates of jump risk may be larger than estimates based on historical data.

We also find evidence of a significant nondefault component in corporate spreads. This result is robust to the choice of the riskless curve. We find that the nondefault component is time varying and mean reverts rapidly. The nondefault component of spreads is strongly related to measures of bond-specific illiquidity such as the bid/ask spread and the outstanding principal amount. In addition, changes in the nondefault component are related to measures of Treasury richness such as the on-the-run/offthe-run spread as well as to measures of the overall liquidity of fixed income markets such as the flows into money market mutual funds. In contrast, there is only weak support for the hypothesis that the nondefault component is due to taxes.

These results have many implications both for asset pricing as well as corporate finance. For example, these results add to the rapidly-growing literature on the effects of liquidity on security prices. Furthermore, the evidence that liquidity effects add to the equilibrium cost of corporate debt is important since it may help explain why firms tend to use less debt in their capital structure than models based on the tradeoff between the costs of financial distress and the tax benefits of debt would suggest (see Leland (1994), Leland and Toft (1996), and Goldstein, Ju, and Leland (2001)). Also, the evidence of systematic time variation in the liquidity component of corporate spreads may shed light on the tendency of corporate debt and equity offerings to cluster. 


\section{APPENDIX A}

From the independence assumption,

$$
\begin{aligned}
& E\left[\exp \left(-\int_{0}^{T} r_{t}+\lambda_{t}+\gamma_{t} d t\right)\right] \\
& =D(T) E\left[\exp \left(-\int_{0}^{T} \lambda_{t} d t\right)\right] E\left[\exp \left(-\int_{0}^{T} \gamma_{t} d t\right)\right] .
\end{aligned}
$$

Let $F(\lambda, T)$ denote the first expectation on the right-hand side of (A1). As in Cox, Ingersoll, and Ross (1985), $F(\lambda, T)$ satisfies the partial differential equation,

$$
\frac{\sigma^{2}}{2} \lambda F_{\lambda \lambda}+(\alpha-\beta \lambda) F_{\lambda}-\lambda F-F_{T}=0
$$

subject to the boundary condition $F(\lambda, 0)=1$. Represent $F(\lambda, T)$ as $A(T) \exp (B(T) \lambda)$. Differentiating this expression and substituting into the partial differential equation shows that this will be a solution provided that $A(T)$ and $B(T)$ satisfy the Riccati equations,

$$
\begin{aligned}
& B^{\prime}=\frac{\sigma^{2}}{2} B^{2}-\beta B-1, \\
& A^{\prime}=\alpha A B,
\end{aligned}
$$

subject to $A(0)=1$ and $B(0)=0$. These two ordinary differential equations are easily solved by direct integration. The solutions to these are as given in Eq. (8). Now let $V(\gamma, T)$ denote the second expectation on the right-hand side of Eq. (A1). $V(\gamma, T)$ satisfies the partial differential equation

$$
\frac{\eta^{2}}{2} V_{\gamma \gamma}-\gamma V-V_{T}=0
$$

subject to the boundary condition $V(\gamma, 0)=1$. Represent $V(\gamma, T)$ as $C(T) \exp (L(T) \gamma)$. Differentiating this expression and substituting it into the partial differential equation shows that this will be a solution provided that $C(T)$ and $L(T)$ satisfy the Riccati equations,

$$
\begin{aligned}
& L^{\prime}=-1, \\
& C^{\prime}=\frac{\eta^{2}}{2} L^{2} C,
\end{aligned}
$$


subject to the boundary conditions $C(0)=1$ and $L(0)=0$. These two ordinary differential equations are easily solved by direct integration. Substituting the solutions back into the definition for $V(\gamma, T)$ implies that $V(\gamma, T)=C(T) \exp (-\gamma T)$, where $C(T)$ is as defined in Eq. (8) (here $L(T)=-T$ ).

Again, from the independence assumption,

$$
\begin{aligned}
& E\left[\lambda_{T} \exp \left(-\int_{0}^{T} r_{t}+\lambda_{t}+\gamma_{t} d t\right)\right] \\
& =D(T) V(\gamma, T) E\left[\lambda_{T} \exp \left(-\int_{0}^{T} \lambda_{t} d t\right)\right] .
\end{aligned}
$$

Let $W(\lambda, T)$ denote the expectation on the right hand side of (A8). Duffie, Pan, and Singleton (2000) implies that $W(\lambda, T)$ satisfies the partial differential equation,

$$
\frac{\sigma^{2}}{2} \lambda W_{\lambda \lambda}+(\alpha-\beta \lambda) W_{\lambda}-\lambda W-W_{T}=0,
$$

subject to the boundary condition $W(\lambda, 0)=\lambda$. Now represent $W(\lambda, T)$ as $\exp (B(T) \lambda)$ $(G(T)+H(T) \lambda)$. Again, differentiating and substituting into the partial differential equation shows that this is a solution provided that $B(T), G(T)$ and $H(T)$ satisfy the Riccati equations,

$$
\begin{aligned}
B^{\prime} & =\frac{\sigma^{2}}{2} B^{2}-\beta B-1, \\
H^{\prime} & =H\left(\alpha+\sigma^{2}\right) B-H \beta, \\
G^{\prime} & =\alpha B G+\alpha H,
\end{aligned}
$$

subject to $B(0)=G(0)=0$, and $H(0)=1$. The equation for $B^{\prime}$ in (A10) is the same as in (A3) and has the same solution. Eq. (A11) can now be solved for $H(T)$ by integration. Finally, with these expressions for $B(T)$ and $H(T)$, the function $G(T)$ can also be solved by a direct integration. The resulting solutions are as given in Eq. (8) of the text.

Substituting these expressions for $F(\lambda, T), V(\gamma, T)$, and $W(\lambda, T)$ into Eqs. (4) and (7) gives the solutions for the value of the corporate bond shown in Eq. (8) and the credit-default swap premium shown in Eq. (9). 


\section{APPENDIX B}

\section{Credit-Default Swap Data.}

The credit-default swap data for the study is taken from an extensive data set of premia for five-year contracts provided by Citigroup that includes observations for the time period from March 15, 2001 to October 9, 2002. (Enron is the sole exception in that its credit-default swap data begins on December 5, 2000). Before September 26, 2001, the data consist of Thursday quotations. After September 26, 2001, the data are recorded on Wednesday. There is one period during the sample period where only a few firms have credit-default swap premia quotations recorded. This is the period from December 5, 2001 to January 2, 2002.

\section{Bond Yield Data.}

In collecting bond yield data, the following criteria are applied.

- Only SEC-registered dollar-denominated issues are included.

- Medium term notes are avoided where possible.

- Only fixed coupon issues are used.

- Where possible, larger issues are chosen. Issues with total notional amount less than $\$ 10$ million are excluded. The issue sizes range from a low of $\$ 18$ million to a high of $\$ 6.5$ billion, with a mean of $\$ 735$ million and a median of $\$ 500$ million.

- Bonds with callable or puttable features are excluded. The only exceptions are bonds with a make-whole provision. A make-whole provision stipulates that if the issuer calls the bond, the amount paid for the call is based on a yield computed as a specific spread over Treasuries. Thus, the call price moves inversely with interest rates, making refunding less likely (see Fabozzi (2001) pg. 11).

- At least two bonds need to be included in the bracketing set for a firm to be included in the sample.

The algorithm for identifying candidate bonds for inclusion in the bracketing set is as follows. We first attempt to find a bond with a maturity shorter than five years as of the first observation date for each firm. In most cases, this involves finding a bond with a maturity date before March 15, 2006 which can then be used as the lower limit of the bracketing interval. Maturity dates of bonds used for the lower limit range from 2003 to 2006. Similarly, we then attempt to find a bond with a maturity longer than five years as of the last observation date for each firm. This last observation date is typically October 9, 2002. The maturity of this bond is then used as the upper limit of the bracketing interval. Maturity dates for bonds used for the upper limit range from 2007 to 2011. Once the bonds defining the lower and upper limits of the bracketing interval are identified, bonds with intermediate maturity dates are identified to provide roughly equally-spaced coverage of the entire bracketing interval. To be included in the bracketing set, the candidate bonds identified in this manner also need to satisfy 
the criteria described above.

The yield data obtained from Citigroup have missing observations for some bonds on some dates. The yield data are checked against yield data from Bloomberg and the agreement is generally reasonable. For dates where the yields diverge significantly, the observation is deleted from the sample.

Some filtering of the bond yield data is necessary. Most of the filtering concerns yields which change by large amounts on a given date compared to the yields of the other bonds for the firm. In these cases, the yields for those bonds are removed from the sample for that date. In other cases, part or all of the time series of yields for a particular bond is removed from the sample. Typically, this is because part or all of the time series of yields for the bond exhibits large movements that are clearly inconsistent with the movements of other bonds for that firm. Three firms deserve special mention in this regard. Qwest Capital, Sprint, and Worldcom were in severe financial distress during the latter part of our sample period. During this period, the yield data for these companies exhibited what was clearly asynchronous updating. Week-to-week changes in various yields often differed by hundreds of basis points. Because of this, their yield data during these time periods are not included in the sample. For Qwest Capital, 16 weekly data points remain after the data selection process, covering the period from September 26, 2001 to January 30, 2002. For Sprint, 33 weekly data points remain after the data selection process, covering the period from March 29, 2001 to February 6, 2002. For Worldcom, 33 weekly data points remain after the data selection process, covering the period from March 15, 2001 to January 23, 2002. Worldcom filed for bankruptcy on July 21, 2002.

There are two mergers during the sample period. TRW was acquired by NorthrupGrumman. The completion date of the merger was December 12, 2002, which is after the end of the sample. Thus, only bonds with TRW as the issuer are used. Conoco was acquired by Conoco-Phillips. The completion date for the merger was September 3,2002 , which is a few weeks before the end of the data set. Bonds with Conoco as the issuer are used throughout the sample. 


\section{REFERENCES}

Acharya, Viral V., and Lasse Heje Pedersen, 2003, Asset Pricing with Liquidity Risk, Working paper, London Business School.

Acharya, Viral V., Sanjiv R. Das, and Rangarajan K. Sundaram, 2002, Arbitrage-Free Pricing of Credit Derivatives with Rating Transitions, Financial Analysts Journal $58,28-44$.

Amihud, Yakov, and Mendelson, Haim, 1991, Liquidity, Maturity, and the Yields on U. S. Treasury Securities. The Journal of Finance 46, 1411-25.

Blanco, Roberto, Simon Brennan, and Ian W. Marsh, 2003, An Empirical Analysis of the Dynamic Relationship Between Investment Grade Bonds and Credit Default Swaps, Working paper, Bank of England.

Buraschi, Andrea, and Davide Menini, 2002, Liquidity Risk and Special Repos: How Well do Forward Repo Spreads Price Future Specialness?, Journal of Financial Economics $64,243-284$.

British Bankers' Association, 2002, BBA Credit Derivatives Report 2001/2002.

Collin-Dufresne, Pierre, Robert S. Goldstein, and J. Spencer Martin, 2001, The Determinants of Credit Spread Changes, Journal of Finance 56, 2177-2207.

Collin-Dufresne, Pierre, Robert S. Goldstein, and Jean Helwege, 2003, Is Credit Event Risk Priced? Modeling Contagion via the Updating of Beliefs, Working paper, Carnegie Mellon University.

Cossin, Didier, Tomas Hricko, Daniel Aunon-Nerin, and Zhijiang Huang, 2002, Exploring for the Determinants of Credit Risk in Credit Default Swap Transaction Data: Is Fixed-Income Markets' Information Sufficient to Evaluate Credit Risk?, Working paper, HEC, University of Lausanne.

Cox, John C., Jonathan E. Ingersoll, and Stephen A. Ross, 1985, A Theory of the Term Structure of Interest Rates, Econometrica 53, 385-407.

Das, Sanjiv R., 1995, Credit Risk Derivatives, Journal of Derivatives 2, 7-21.

Das, Sanjiv R., and Rangarajan K. Sundaram, 2000, A Discrete-Time Approach to Arbitrage-Free Pricing of Credit Derivatives, Management Science 46, 46-62.

Das, Sanjiv R., Rangarajan K. Sundaram, and Suresh M. Sundaresan, 2003, A Simple Unified Model for Pricing Derivative Securities with Equity, Interest-Rate, and Default Risk, Working paper, Santa Clara University. 
Das, Sanjiv R., and Peter Tufano, 1996, Pricing Credit Sensitive Debt when Interest Rates, Credit Ratings and Credit Spreads are Stochastic, Journal of Financial Engineering 5, 161-198.

Delianedis, Gordon, and Robert Geske, 2001, The Components of Corporate Credit Spreads: Default, Recovery, Tax, Jumps, Liquidity, and Market Factors, Working paper, UCLA.

Duffee, Gregory R., 1999, Estimating the Price of Default Risk, Review of Financial Studies 12, 197-226.

Duffie, Darrell, 1996, Special Repo Rates, Journal of Finance 51, 493-526.

Duffie, Darrell, 1998, Defaultable Term Structure Models with Fractional Recovery of Par, Working paper, Stanford University.

Duffie, Darrell, 1999, Credit Swap Valuation, Financial Analysts Journal 55, 73-87.

Duffie, Darrell, Nicolae Garleanu, and Lasse Heje Pedersen, 2002, Securities Lending, Shorting, and Pricing, Journal of Financial Economics 66, 307-339.

Duffie, Darrell, and Jun Liu, 2001, Floating-Fixed Credit Spreads, Financial Analysts Journal 57, 76-87.

Duffie, Darrell, Jun Pan, and Kenneth J. Singleton, 2000, Transform Analysis and Asset Pricing for Affine Jump-Diffusions, Econometrica 68, 1343-1376.

Duffie, Darrell, and Kenneth J. Singleton, 1997, An Econometric Model of the Term Structure of Interest-Rate Swap Yields, Journal of Finance 52, 1287-1321.

Duffie, Darrell, and Kenneth J. Singleton, 1999, Modeling Term Structures of Defaultable Bonds, Review of Financial Studies 12, 687-720.

Elton, Edwin J., Martin J. Gruber, Deepak Agrawal, and Christopher Mann, 2001, Explaining the Rate Spread on Corporate Bonds, The Journal of Finance 56, 247277.

Eom, Young Ho, Jean Helwege, and Jing-zhi Huang, 2003, Structural Models of Corporate Bond Pricing: An Empirical Analysis, Review of Financial Studies, forthcoming.

Fabozzi, Frank J., 2001, Handbook of Fixed Income Securities, 6th Ed., McGraw-Hill Publishers, New York.

Fitch IBCA, Duff and Phelps, 2001, Synthetic CDOs: A Growing Market for Credit Derivatives, February 6.

Geczy, Christopher C., David K. Musto, and Adam V. Reed, 2002, Stocks are Special 
Too: An Analysis of the Equity Lending Market, Journal of Financial Economics $66,241-269$.

Goldstein, Robert S., Nengjiu Ju, and Hayne E. Leland, 2001, An EBIT-based Model of Dynamic Capital Structure, Journal of Business 74, 483-512.

Houweling, Patrick, and Ton Vorst, 2004, Pricing Default Swaps: Empirical Evidence, Journal of International Money and Finance, forthcoming.

Huang, Jing-zhi, and Ming Huang, 2003, How Much of the Corporate-Treasury Yield Spread is Due to Credit Risk?, Working paper, Penn State University.

Hull, John, Mirela Predescu, and Alan White, 2004, The Relationship Between Credit Default Swap Spreads, Bond Yields, and Credit Rating Announcements, Journal of Banking and Finance, forthcoming.

Hull, John, and Alan White, 2000, Valuing Credit Default Swaps I: No Counterparty Default Risk, The Journal of Derivatives 8, No. 1, Fall, 29-40.

Hull, John, and Alan White, 2001, Valuing Credit Default Swaps II: Modeling Default Correlations, The Journal of Derivatives 8, No. 3, Spring, 12-22.

J.P. Morgan, 2000, The J.P. Morgan Guide to Credit Derivatives.

Jarrow, Robert A., and Stuart M. Turnbull, 1995, Pricing Derivatives on Financial Securities Subject to Credit Risk, Journal of Finance 50, 53-85.

Jarrow, Robert A., and Stuart M. Turnbull, 2000, The Intersection of Market and Credit Risk, Journal of Banking and Finance 24, 271-299.

Jarrow, Robert A., and Yildiray Yildirim, 2002, Valuing Default Swaps Under Market and Credit Risk Correlation, Journal of Fixed Income 11, 7-19.

Jones, E. Philip, Scott P. Mason, and Eric Rosenfeld, 1984, Contingent Claims Analysis of Corporate Capital Structures: an Empirical Investigation, Journal of Finance 39, 611-625

Jordan, Bradford D., and Susan D. Jordan, 1997, Special Repo Rates: An Empirical Analysis, Journal of Finance 52, 2051-2072.

Kamara, Avraham, 1994, Liquidity, Taxes, and Short-Term Treasury Yields, Journal of Financial and Quantitative Analysis 29, 403-17.

Krishnamurthy, Arvind, 2002, The Bond/Old Bond Spread, Journal of Financial Economics 66, 463-506.

Lando, David, 1998, On Cox Processes and Credit Risky Securities, Review of Deriva- 
tives Research 2, 99-120.

Leland, Hayne E., 1994, Corporate Debt Value, Bond Covenants, and Optimal Capital Structure, Journal of Finance 49, 1213-1252.

Leland, Hayne E., and Klaus Bjerre Toft, 1996, Optimal Capital Structure, Endogenous Bankruptcy, and the Term Structure of Credit Spreads, Journal of Finance 51, 9871019 .

Liu, Jun, Francis A. Longstaff, and Ravit E. Mandell, 2002, The Market Price of Credit Risk: An Empirical Analysis of Interest Rate Swap Spreads, Working paper, UCLA.

Longstaff, Francis A., and Eduardo S. Schwartz, 1995a, A Simple Approach to Valuing Risky Fixed and Floating Rate Debt, The Journal of Finance 50, 789-819.

Longstaff, Francis A., and Eduardo S. Schwartz, 1995b, Valuing Credit Derivatives, The Journal of Fixed Income 5, 6-12.

Longstaff, Francis A., 2004, The Flight-to-Liquidity Premium in U.S. Treasury Bond Prices, Journal of Business, forthcoming.

Mithal, Sanjay, 2002, Single-Name Credit Default Swaps-A Users Guide, Global Credit Derivatives Research, Salomon Smith Barney, Inc.

Norden, Lars, and Martin Weber, 2004, Informational Efficiency of Credit Default Swap and Stock Markets: The Impact of Credit Rating Announcements, Working paper, University of Mannheim.

Pan, Jun, 2002, The Jump-Risk Premia Implicit in Options: Evidence from an Integrated Time-Series Study, Journal of Financial Economics 63, 3-50.

Pastor, Lubos, and Robert F. Stambaugh, 2003, Liquidity Risk and Expected Stock Returns, Journal of Political Economy 111, 642-685.

Sarig, Oded, and Arthur Warga, 1989, Some Empirical Estimates of the Risk Structure of Interest Rates, Journal of Finance 44, 1351-1360.

Wang, Ashley W., 2003, Institutional Equity Flows, Liquidity Risk and Asset Pricing, Working paper, University of California Irvine.

Zhang, Frank X., 2003, What did the Credit Market Expect of Argentina Default? Evidence from Default Swap Data, Working paper, Federal Reserve Board. 


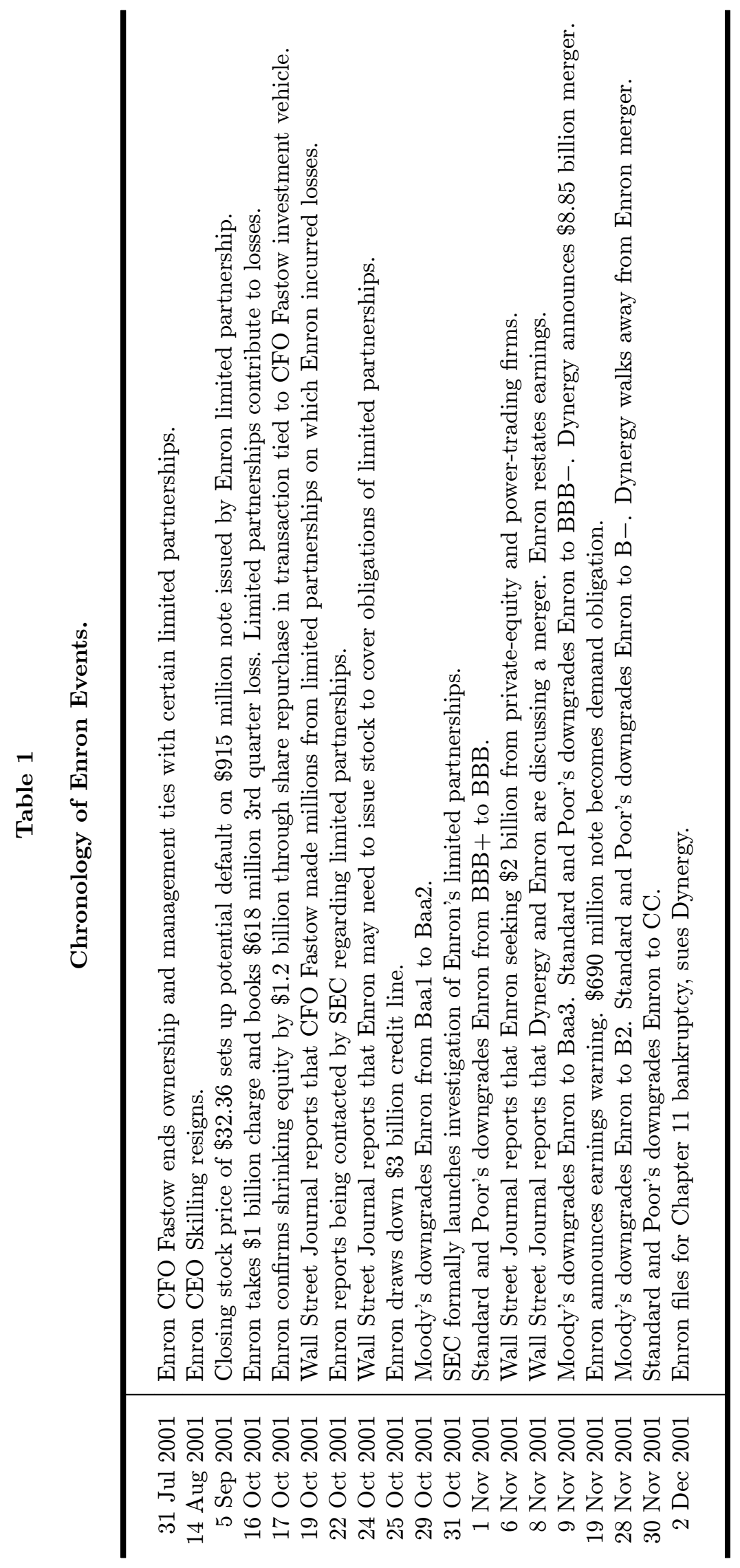




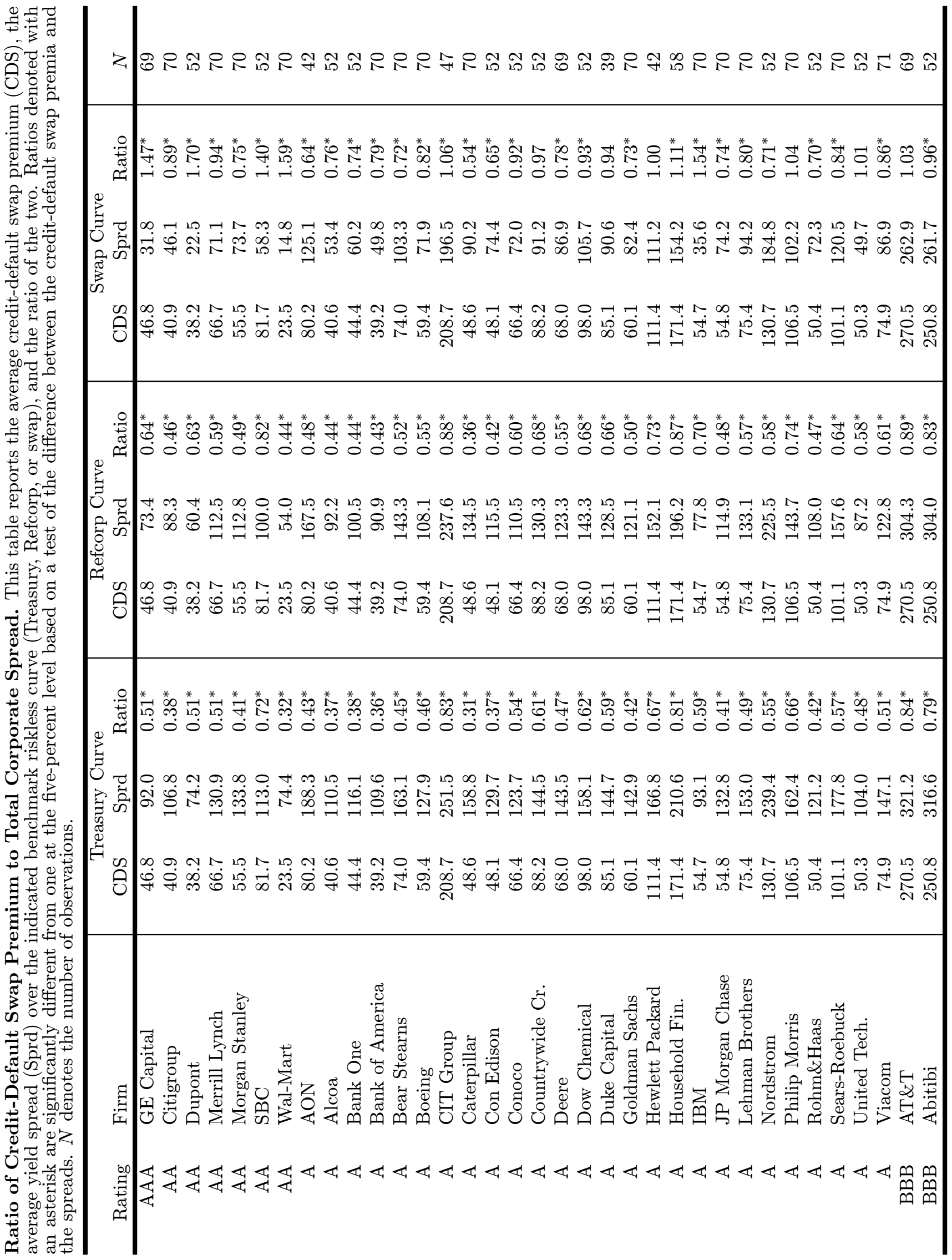




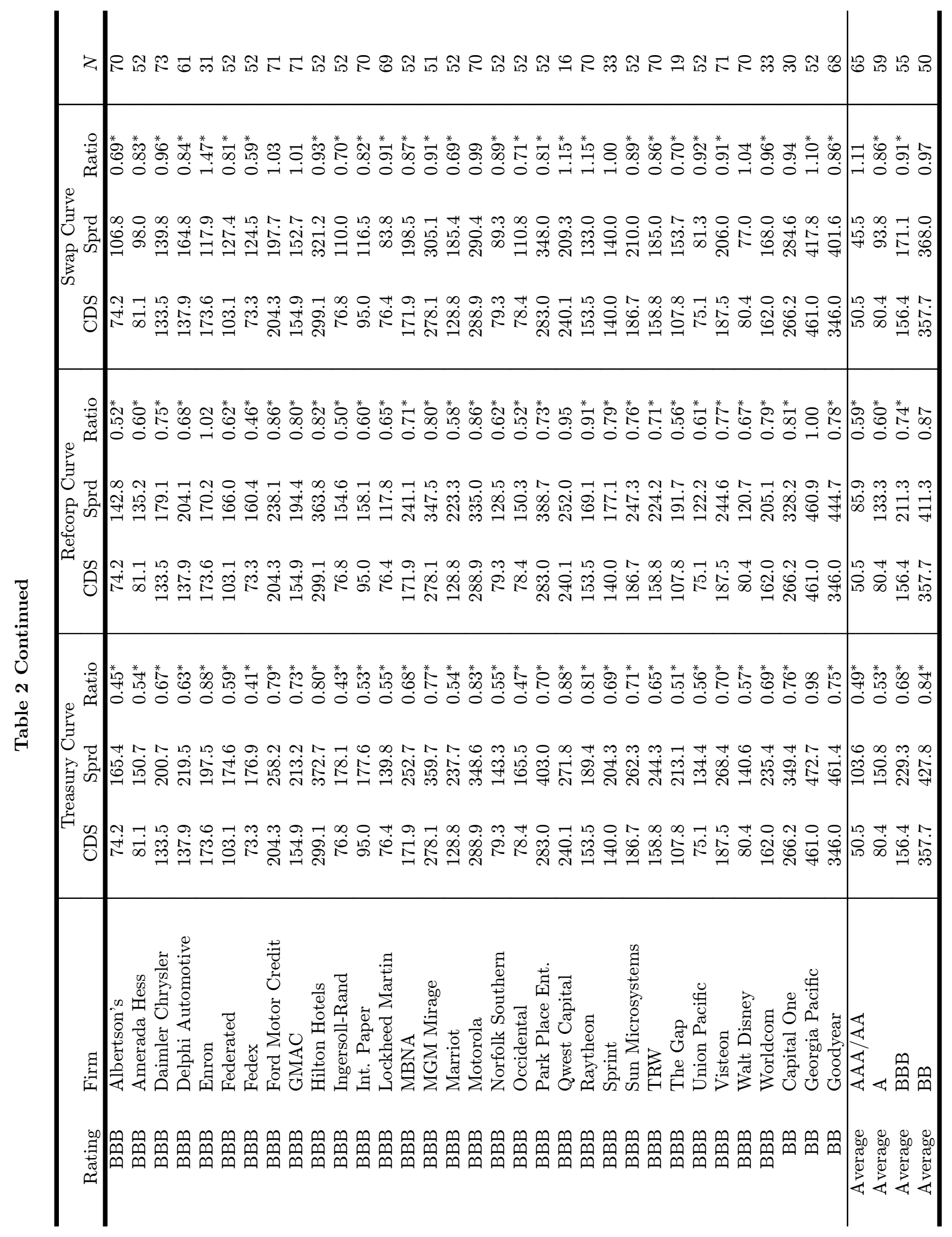




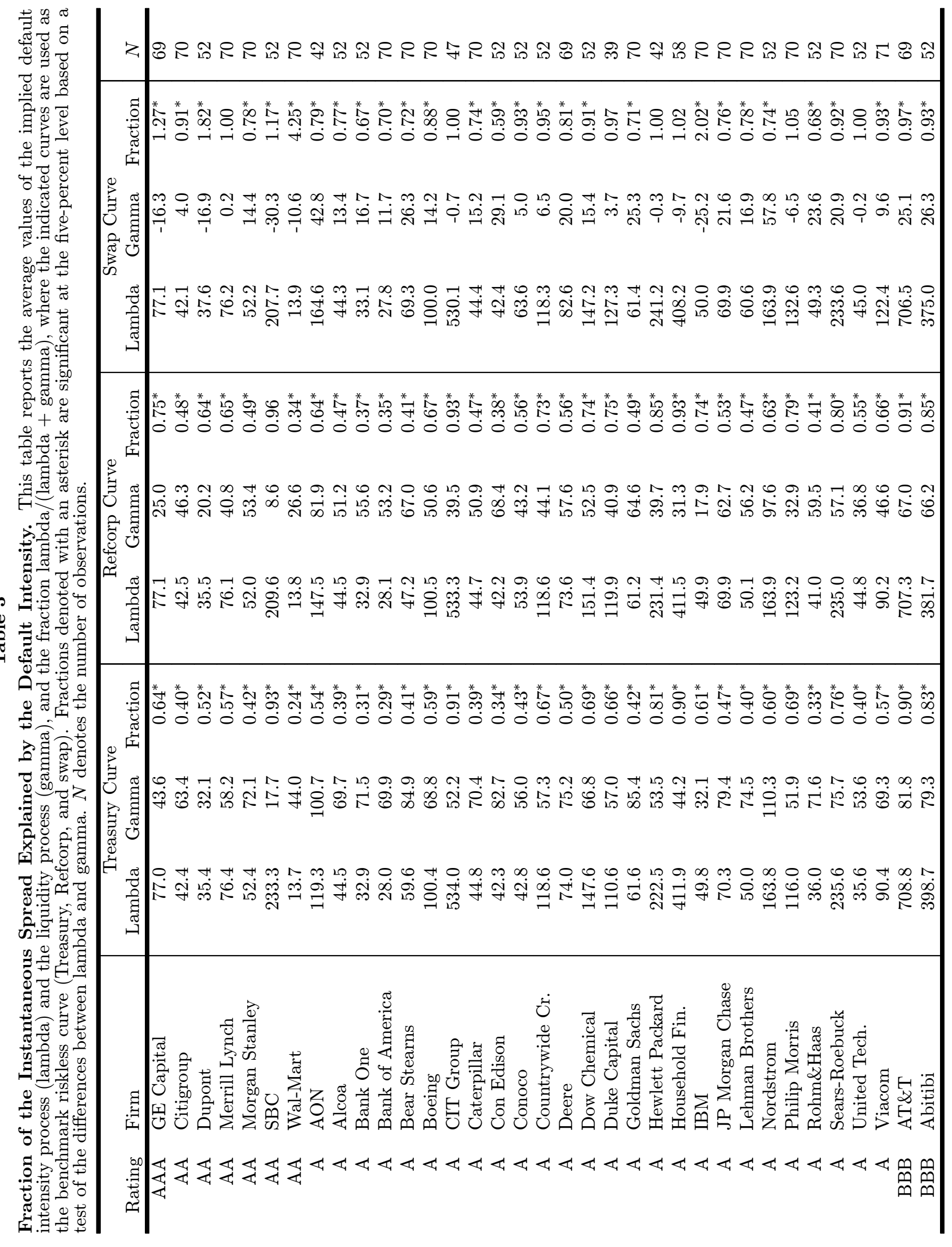




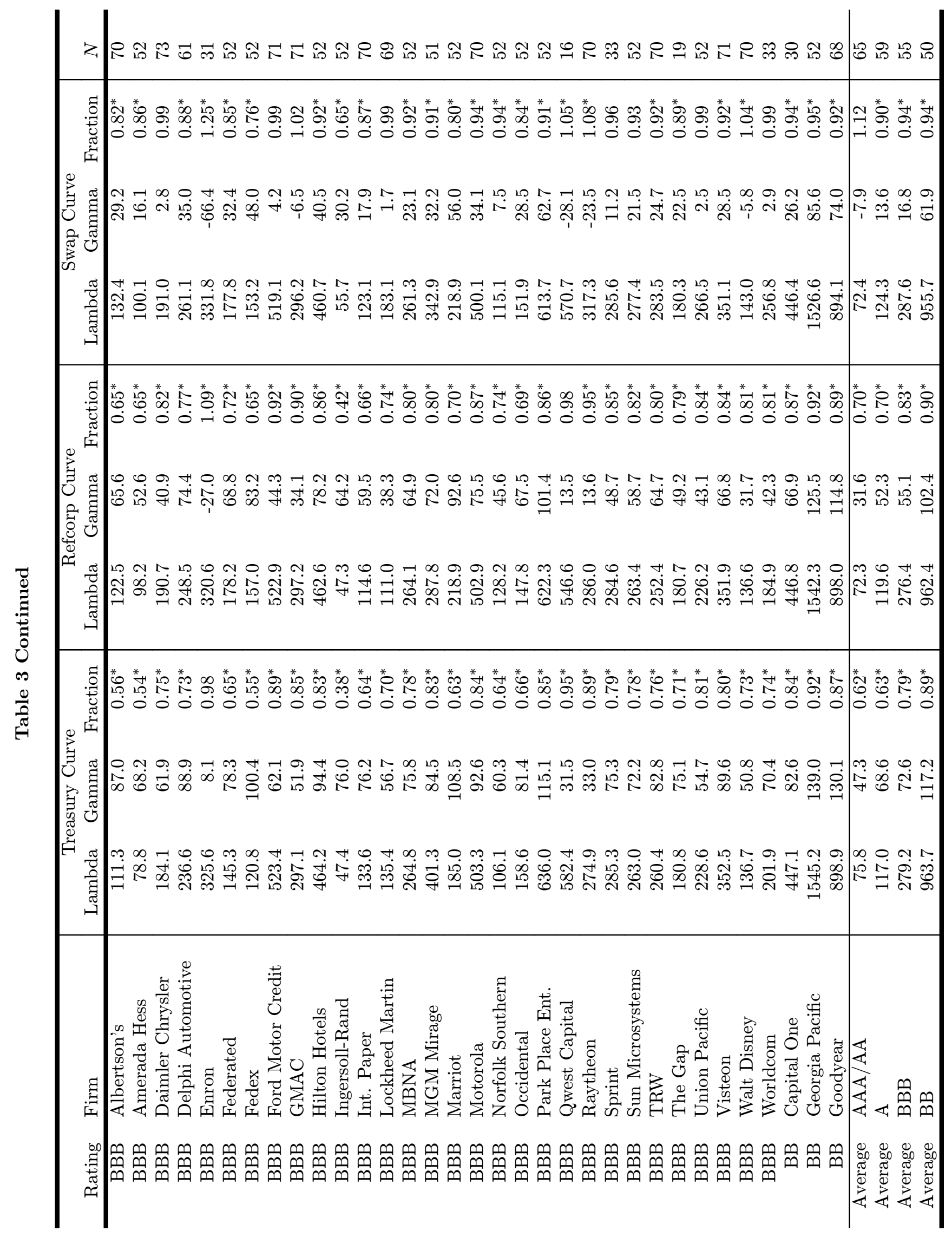




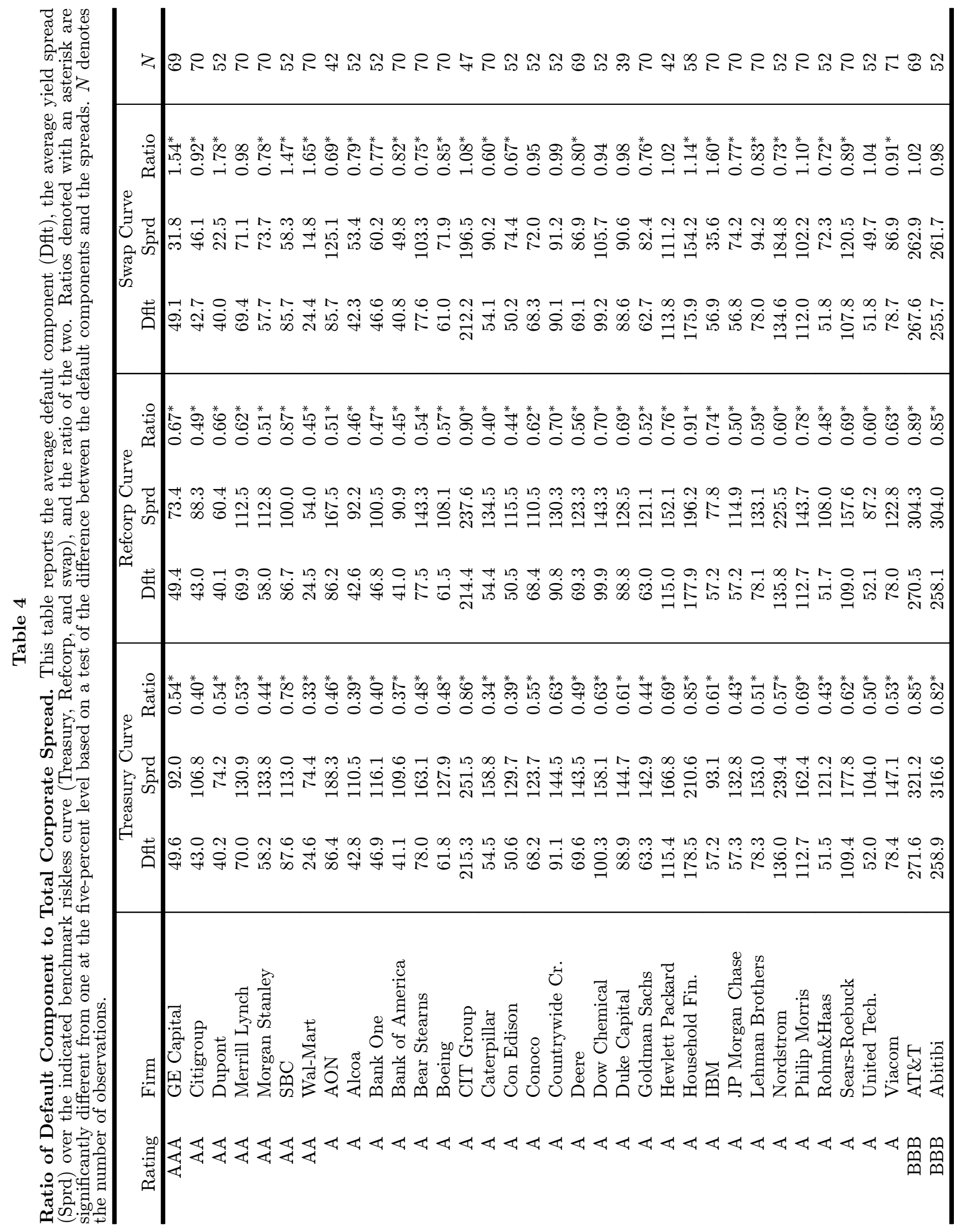




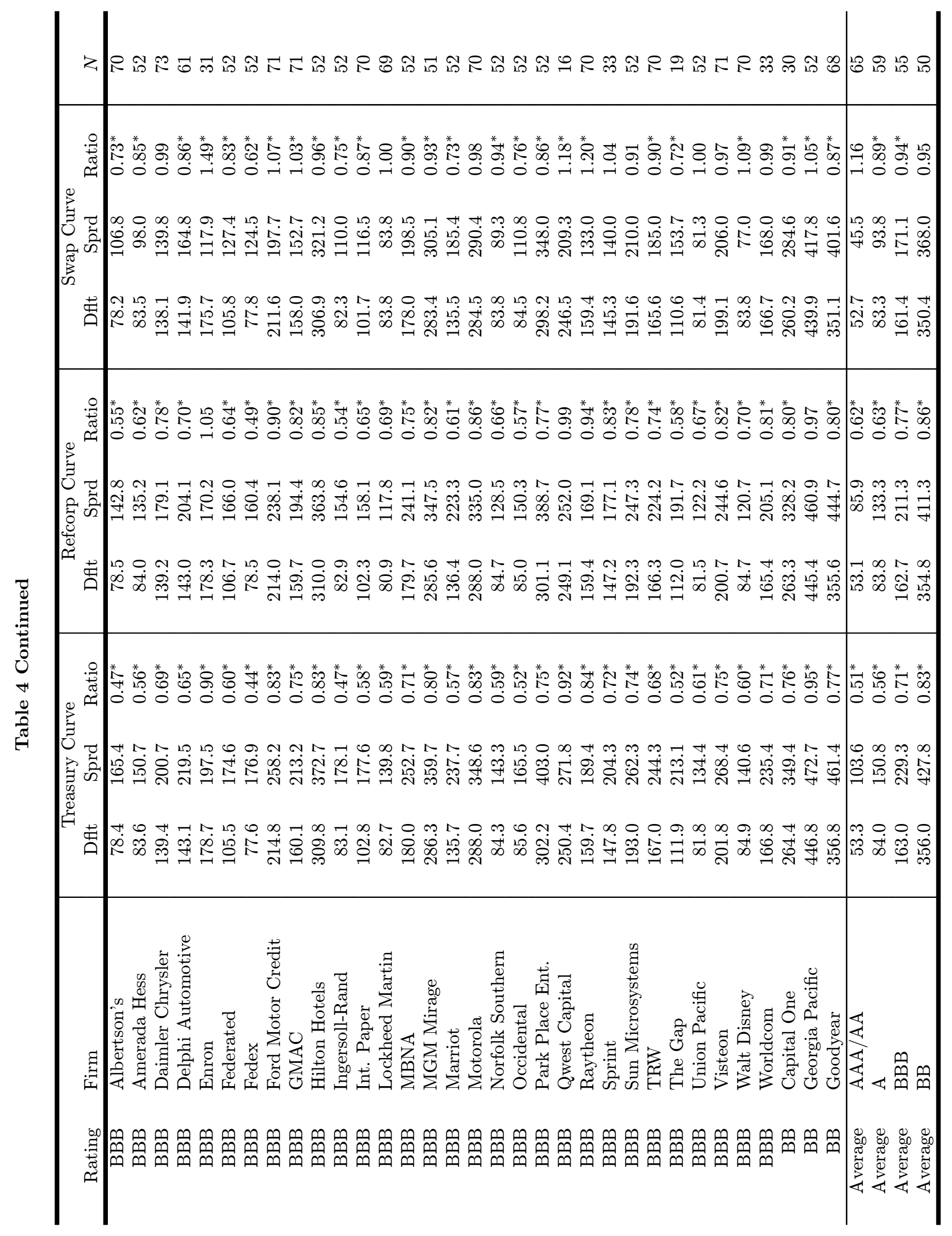




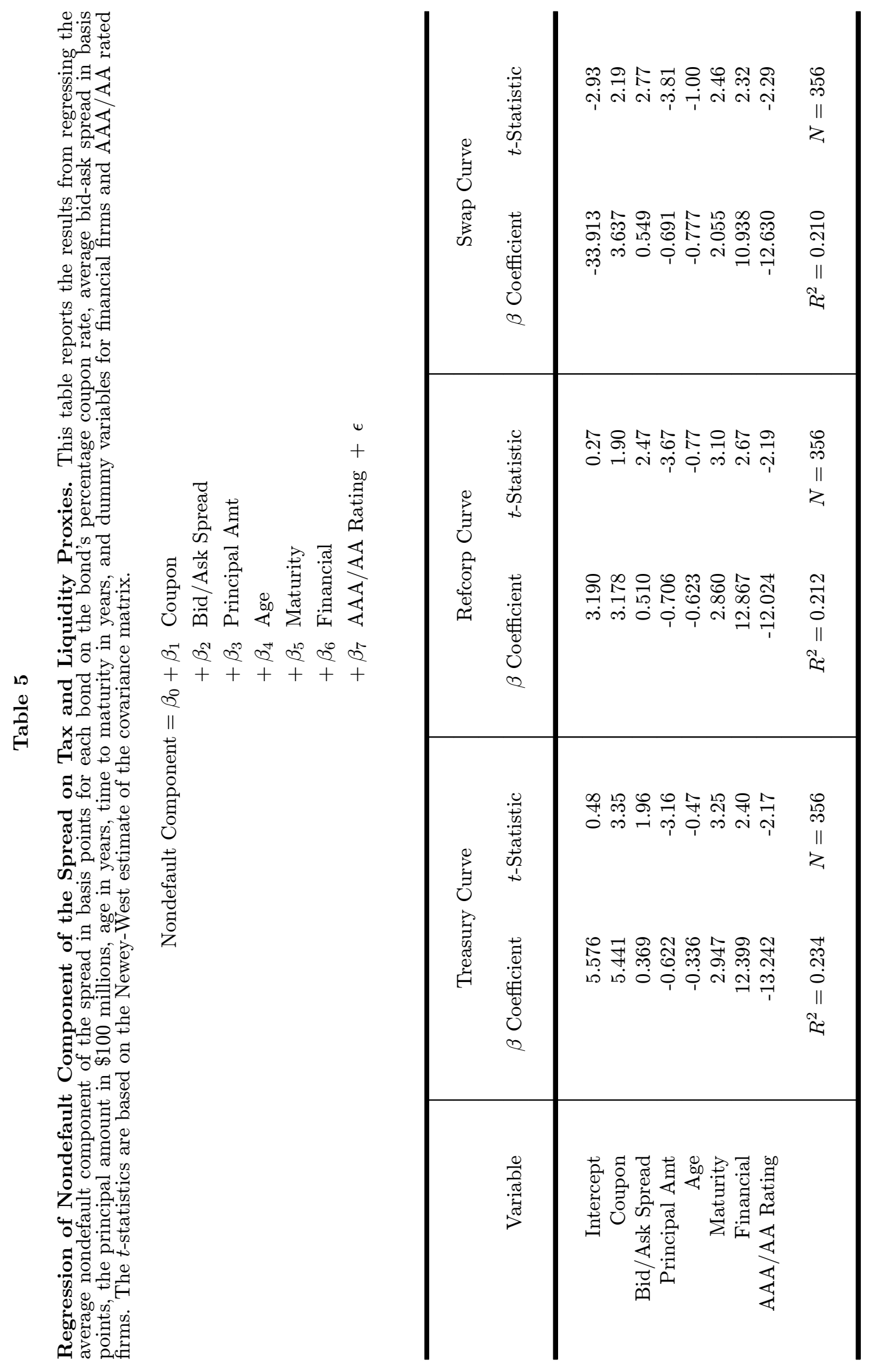




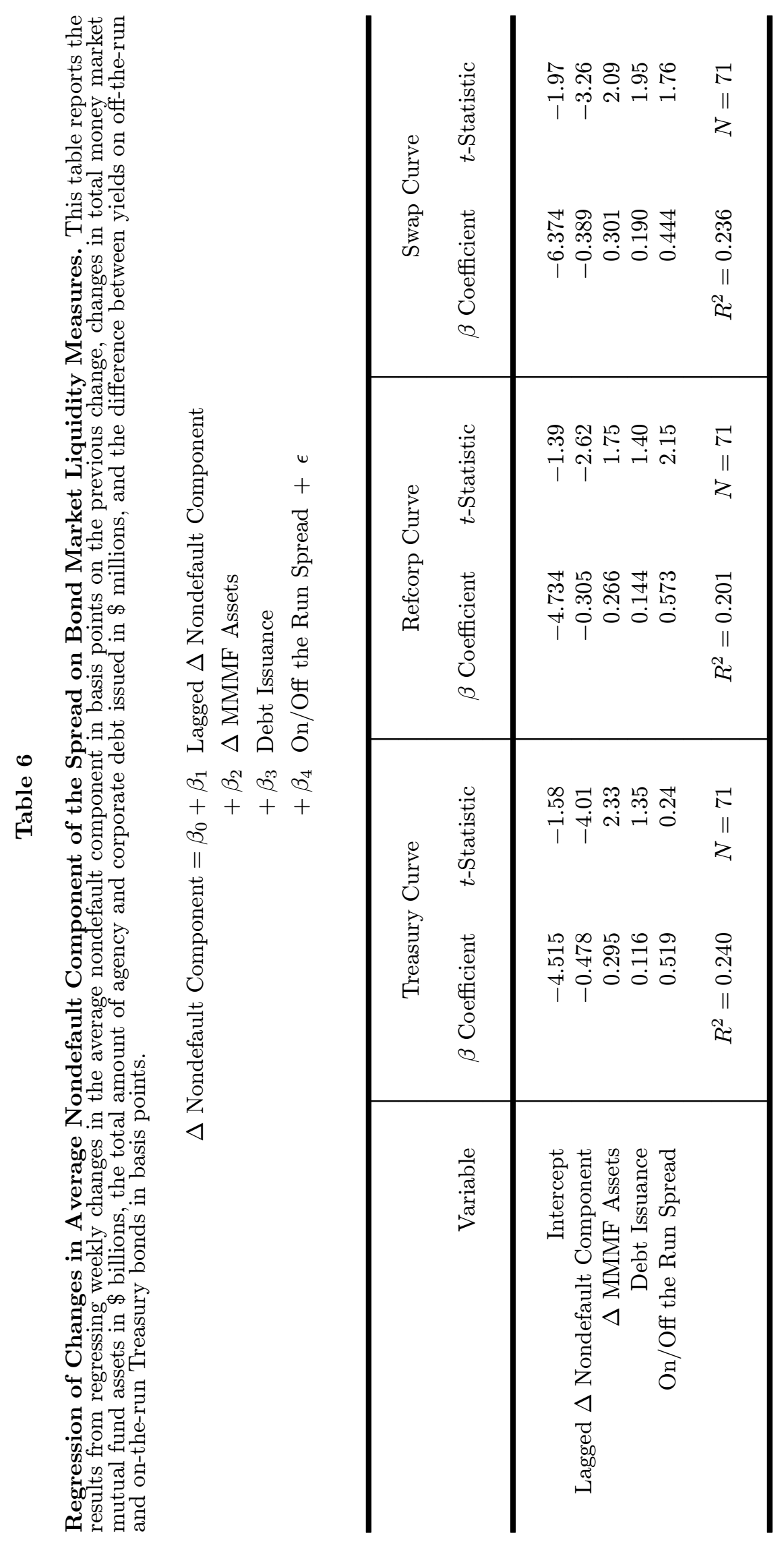



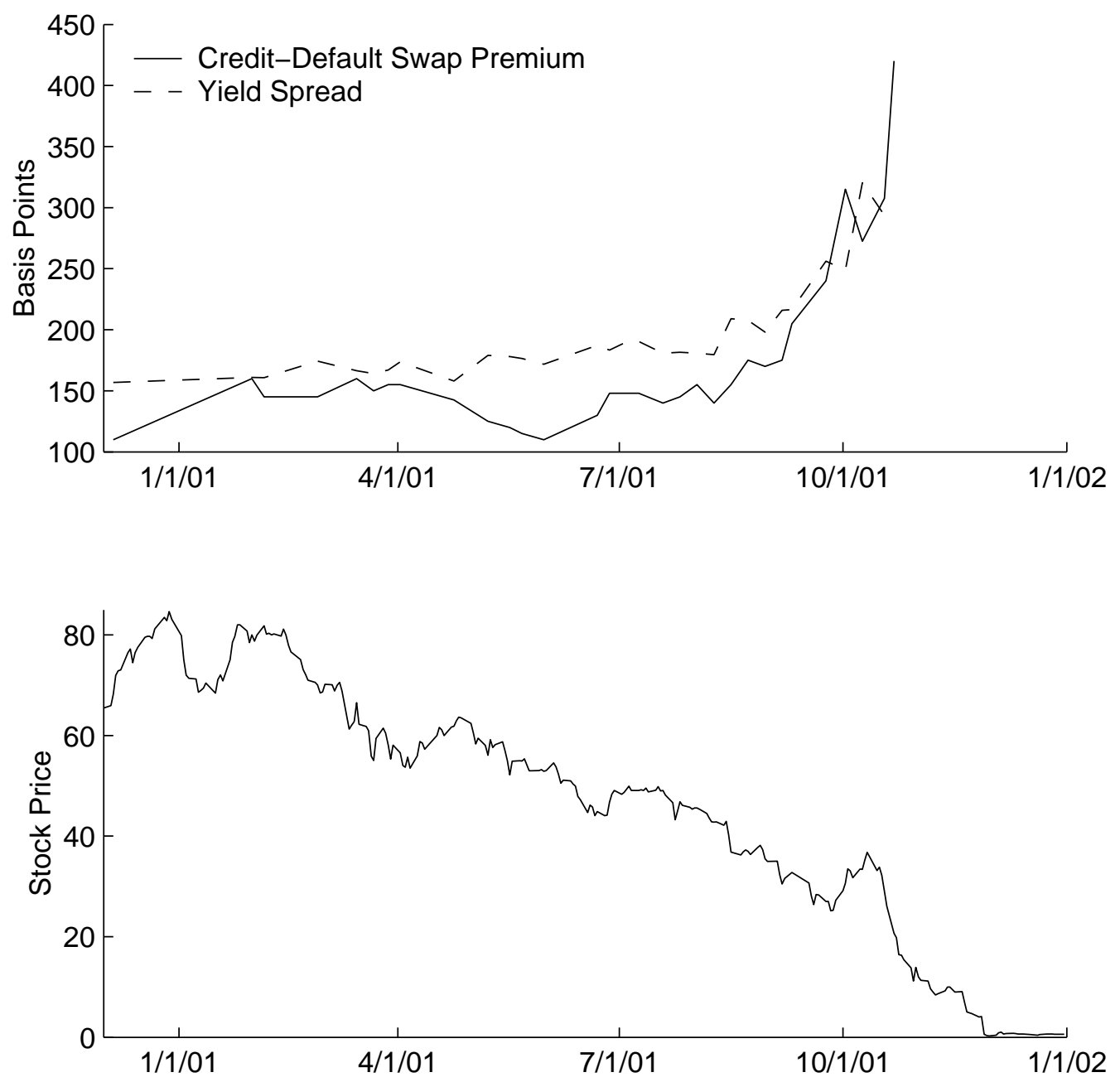

Fig. 1. Time-Series Plot of Enron's Credit-Default Swap Premium, Yield Spread over Treasury, and Stock Price. The top plot shows the time series of Enron's credit-default swap premium and the yield spread over Treasury. The bottom plot shows the times series of Enron's stock price. 

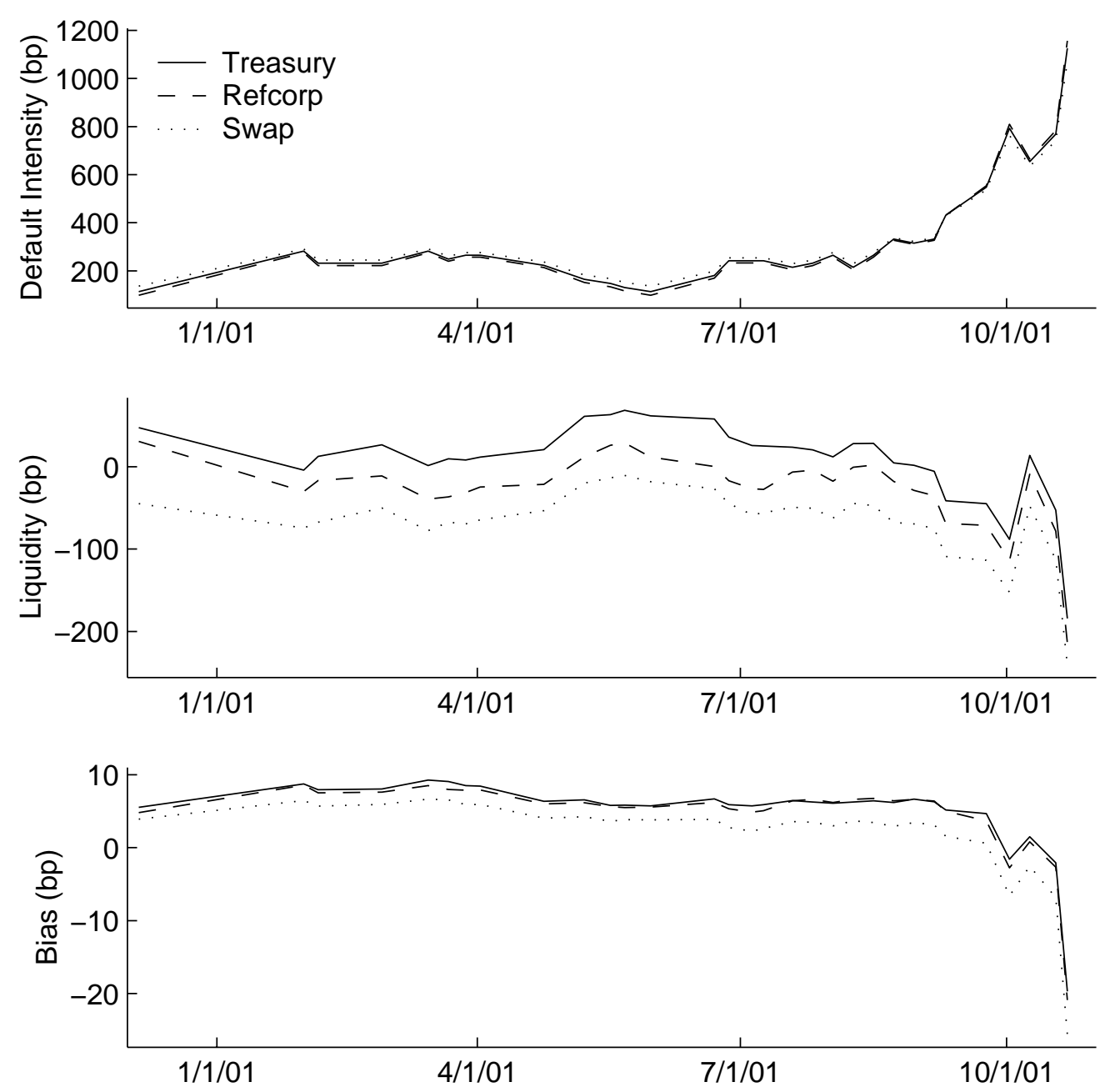

Fig. 2. Time-Series Plot of Enron's Intensity Process, Liquidity Process, and the Difference Between the Default Component and the Credit-Default Swap Premium. The top plot shows the intensity process in basis points for each of the riskless curves. The middle plot shows the liquidity process in basis points for each of the riskless curves. The bottom plot shows the difference between the default component and the credit-default swap premium in basis points, which is the bias caused by using the credit-default swap premium as a measure of the default component of the yield spread. 

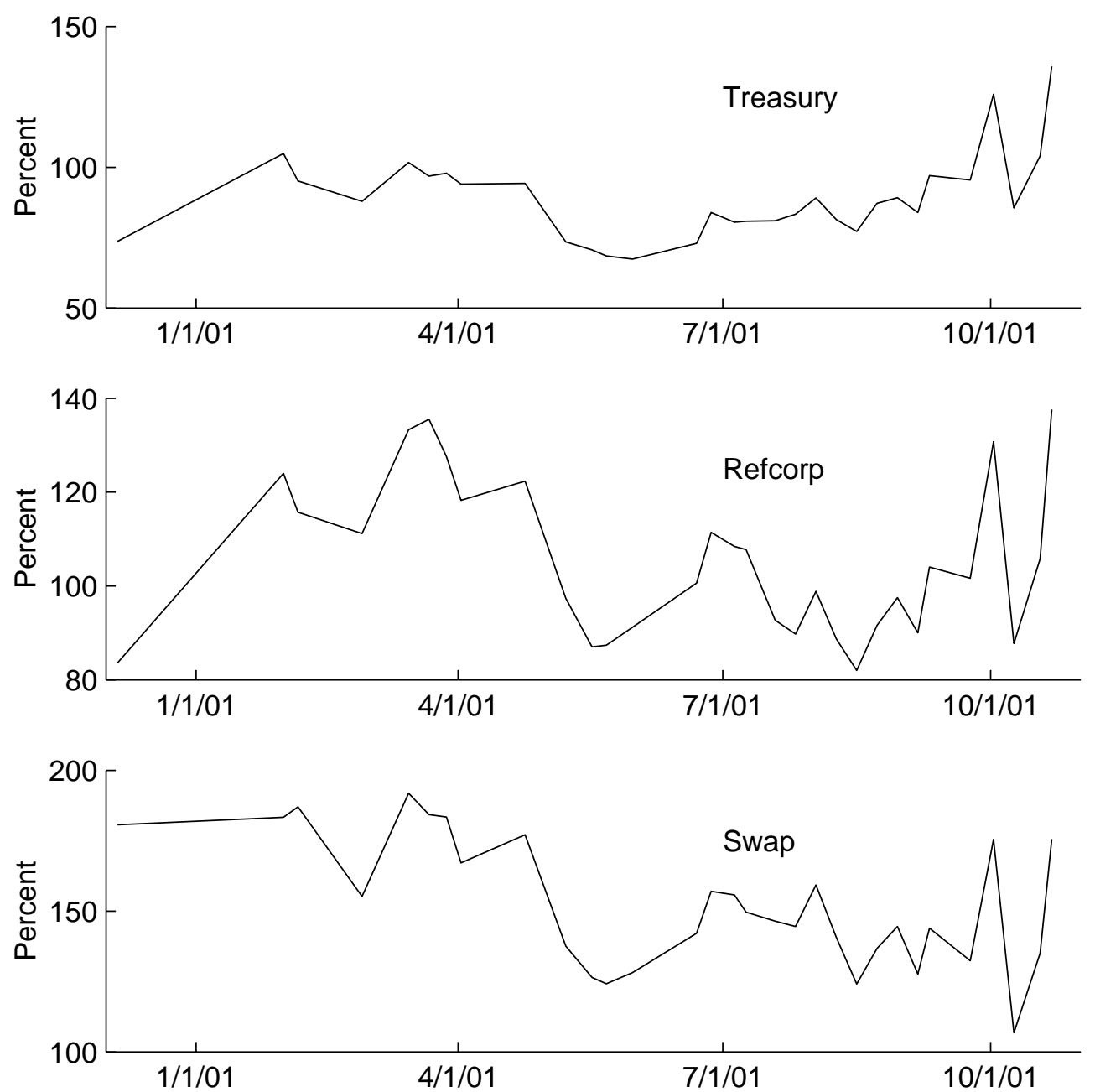

Fig. 3. Time-Series Plot of the Fraction of the Yield Spread Due to Default for Enron. The three plots show the fraction of Enron's yield spread due to the default component for each of the riskless curves. 

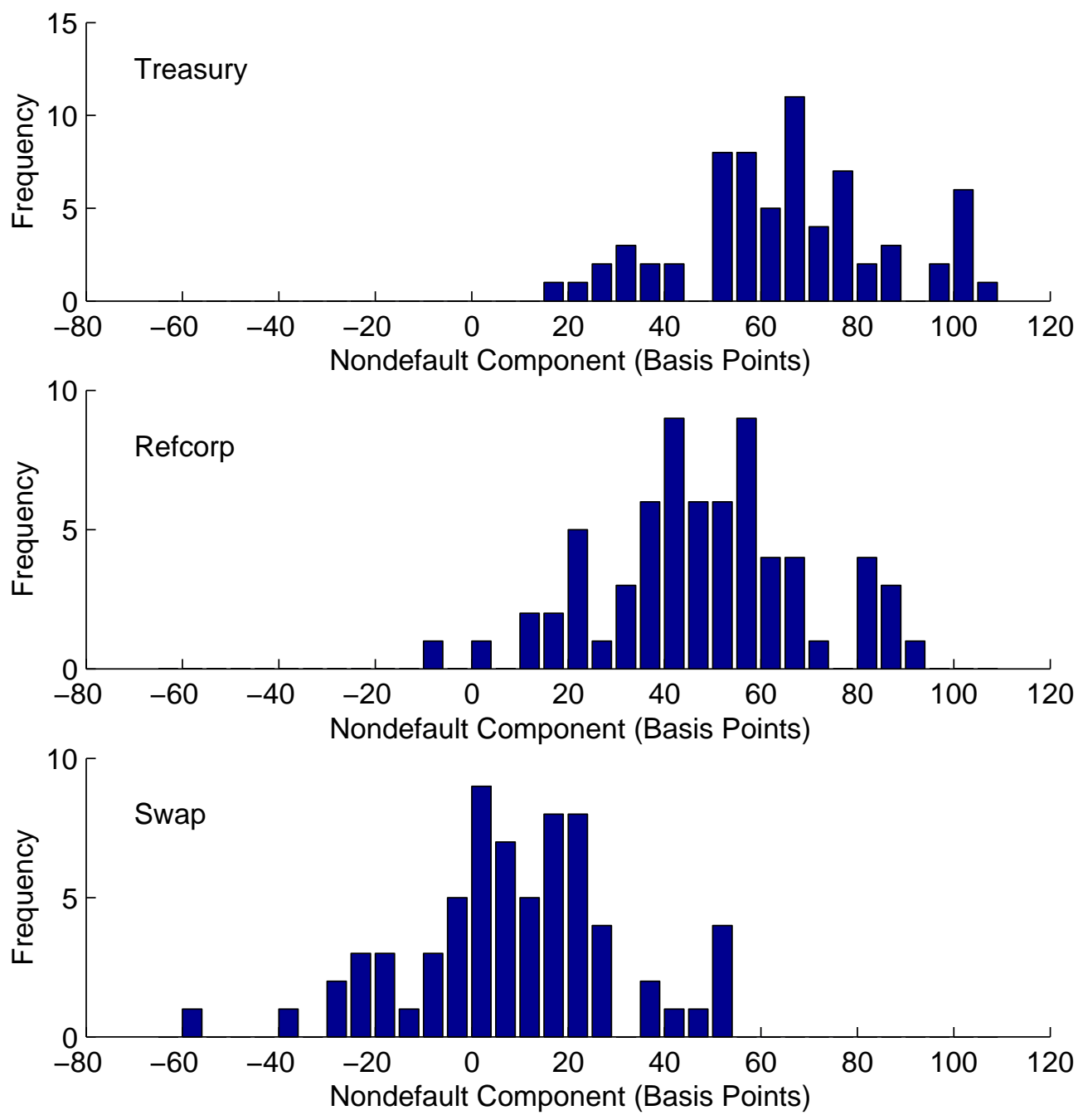

Fig. 4. Distribution of Time-Series-Averaged Nondefault Components. The three plots show the distribution across firms of the time-series average of the nondefault component of the yield spread for the different riskless curves. 

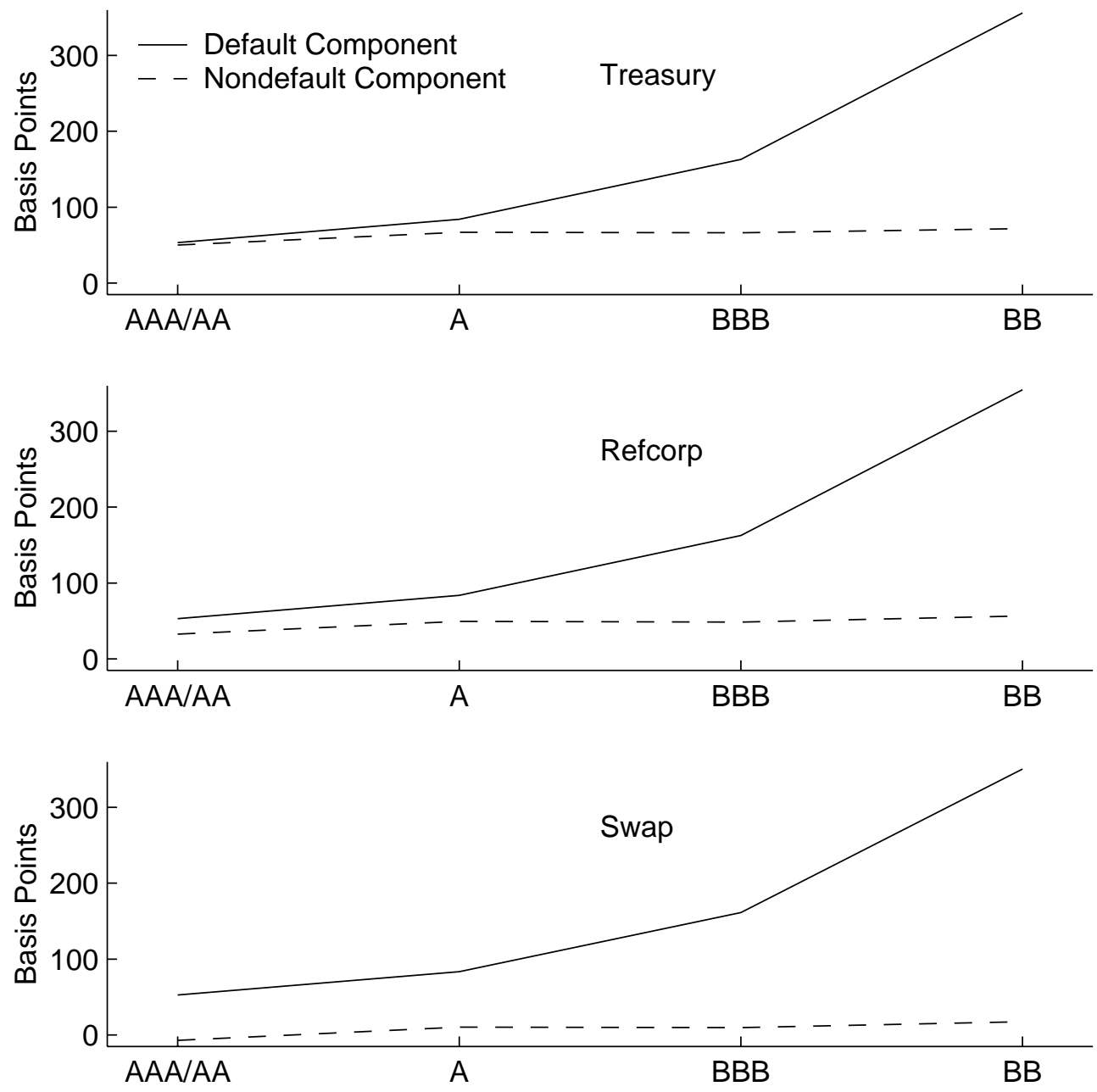

Fig. 5. Plot of Spread Components Versus Ending Rating. The three plots show the default and nondefault components of the yield spread, calculated by averaging over firms with a given ending credit rating. 


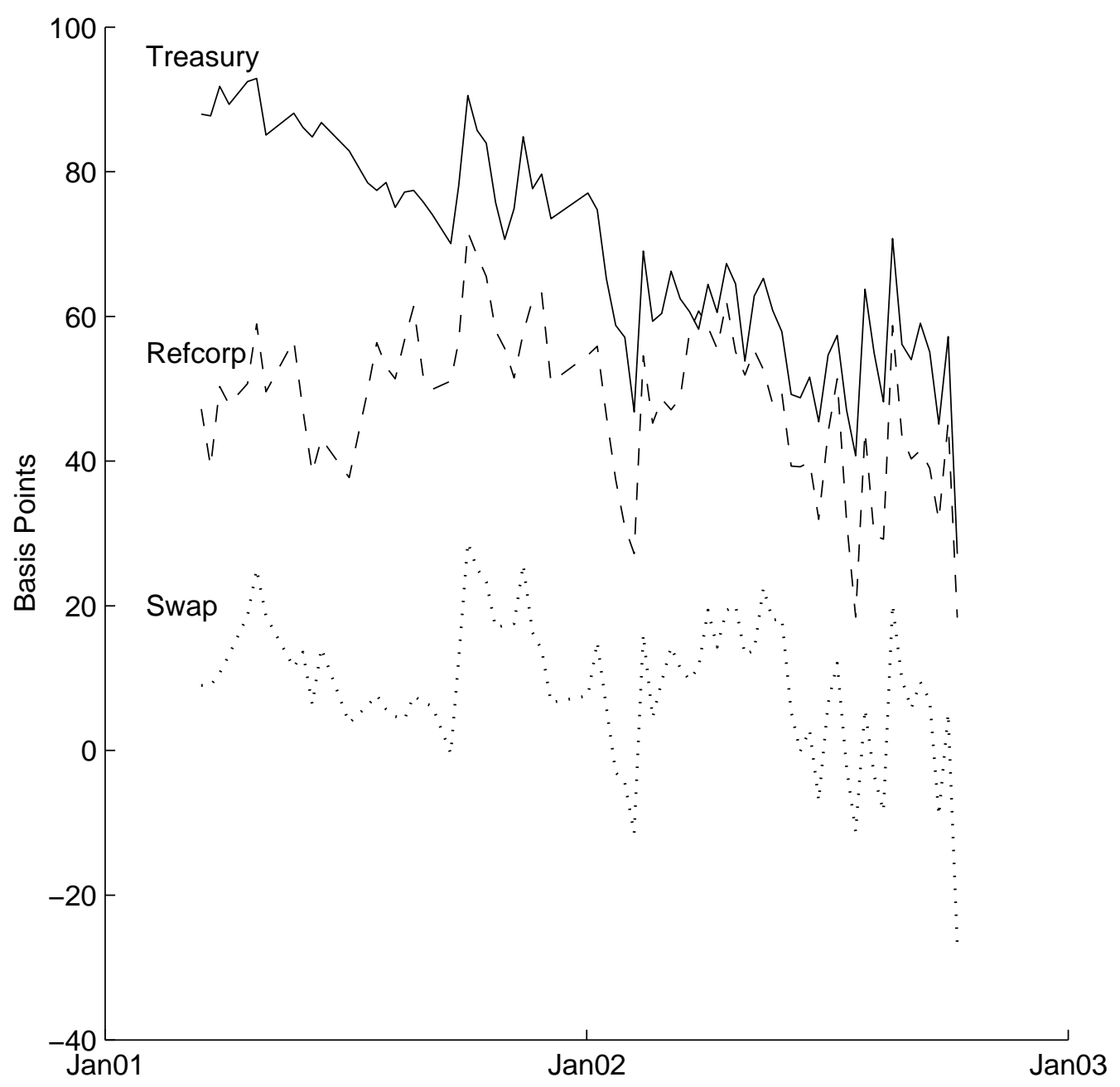

Fig. 6. Time-Series Plot of the Average Nondefault Spread. The plot shows the time series of the nondefault spread averaged over firms for each of the riskless curves. 